\title{
Intermediación turística e intervención administrativa
}

\author{
Carlos Sanz Domínguez \\ Profesor de Derecho Administrativo \\ Universidad de Sevilla
}

\begin{abstract}
SUMARIO: 1. LA DETERMINACIÓN DEL CONCEPTO DE INTERMEDIACIÓN TURÍSTICA EN EL ORDENAMIENTO JURÍDICO. 2. TIPOS DE EMPRESAS DEDICADAS A LA INTERMEDIACIÓN TURÍSTICA. 3. REGULACIÓN LEGAL DE LA INTERMEDIACIÓN TURÍSTICA. 4. LA HABILITACIÓN PARA EL EJERCICIO PROFESIONAL DE LA INTERMEDIACIÓN TURÍSTICA. 5. LA PRECEPTIVA INSCRIPCIÓN DE LAS EMPRESAS DE INTERMEDIACIÓN EN EL REGISTRO ADMINISTRATIVO DE EMPRESAS TURÍSTICAS. 6. RESTRICCIONES IMPUESTAS EN RELACIÓN CON LA FORMA JURÍDICA DE LAS EMPRESAS DEDICADAS A LA INTERMEDIACIÓN TURÍSTICA. 7.IMPOSICIÓN DE LIMITACIONES ECONÓMICAS A LA INTERMEDIACIÓN TURÍSTICA. 8. LA CONCESIÓN DE LA EXCLUSIVIDAD PARA EL EJERCICIO DE DETERMINADAS ACTIVIDADES DE MEDIACIÓN TURÍSTICA. 9. LA TÉCNICA DE LA RESERVA EN EL USO DE TÉRMINOS Y DENOMINACIONES LEGALES RELACIONADAS CON LA INTERMEDIACIÓN TURÍSTICA.
\end{abstract}

\section{LA DETERMINACIÓN DEL CONCEPTO DE INTERMEDIACIÓN TURÍSTICA EN EL ORDENAMIENTO JURÍDICO}

Si bien la regulación jurídica de la intermediación turística, no deja de ser relativamente reciente, puesto que la primera normativa data de 1942, no puede negarse, ni su condición legal de actividad empresarial turística, ni su posición estratégica en el desarrollo del turismo, al servir de necesario nexo de conexión entre una oferta y una demanda habitualmente distante y precisada de medios que faciliten su interrelación ${ }^{1}$. Sin embargo, las Leyes de Turismo

\footnotetext{
${ }^{1}$ En este sentido, RECALDE CASTELLS, A., afirma que "El desarrollo del turismo como un fenómeno de masas está profundamente ligado a la aparición de las agencias de viajes". Vid. "Las agencias de viajes", en GARCÍA MACHO, R. y RECALDE CASTELLS, A. (Dir.), Lecciones de Derecho del Turismo, Tirant lo Blanch, Valencia, 2000, p. 158.
} 
de las distintas Comunidades Autónomas no abordan de forma homogénea la ordenación esencial de la intermediación turística y, por tanto, su propio concepto. Así, un grupo de Leyes parte de su consideración como actividad turística, delimitada como de "intermediación entre el usuario y el ofertante del servicio turístico, así como la organización del producto turístico"2, regulando posteriormente las empresas que se dedican a dicha actividad, entre las que destaca la agencia de viajes. Otras Leyes, aunque optan finalmente por una definición similar, lo hacen partiendo de la consideración inicial de las empresas de intermediación turística, sin concretar previamente la actividad de mediación. El resultado es pues, sustancialmente idéntico: "Se consideran empresas de intermediación turística aquellas que, reuniendo los requisitos que reglamentariamente se determinen, se dedican, profesional y habitualmente, a desarrollar actividades de mediación y organización de servicios turísticos, pudiendo utilizar para ello medios propios"3. Finalmente, en un tercer grupo se encontrarían las Leyes de Turismo que, aun mencionando la intermediación turística dentro de las actividades turísticas o como un tipo de empresa turística, posteriormente sólo alcanzan a ordenar las cuestiones que han considerado de mayor relevancia respecto a las agencias de viajes. En estos supuestos se produce, por vía legal, una equiparación entre intermediación turística y agencia de viajes ${ }^{4}$, provocando, por tanto, una reducción del ámbito subjetivo propio de la mediación en el campo del turismo.

De la regulación de la intermediación turística, en el conjunto de Leyes autonómicas de Turismo, podemos extraer sus caracteres fundamentales. Así, constatamos que se trata de una actividad empresarial, por tanto, será necesario, con carácter previo, proceder a la creación de una empresa, bajo la forma jurídica que, en principio, se estime conveniente, sea individual o colectiva ${ }^{5}$, debiendo cumplir el conjunto de obligaciones que, como actividad empresa-

${ }^{2}$ Art. 25,1 LT Navarra. En el mismo sentido se expresan las Leyes de Turismo de Canarias, Galicia, Comunidad de Madrid y La Rioja.

${ }^{3}$ Art. 49 LT Principado de Asturias. Postura similar mantienen las Leyes de Turismo de Aragón, Andalucía, Cantabria, Castilla y León y Castilla-La Mancha.

${ }^{4}$ Así ocurre en las Leyes de Turismo de Baleares, Cataluña, Extremadura, País Vasco, Región de Murcia y Comunidad Valenciana.

${ }^{5}$ Más adelante trataremos los casos en los que el ordenamiento exige la constitución de una determinada clase de sociedad mercantil para ser titular de una agencia de viajes, excluyendo, por tanto, a las personas naturales y a las entidades que carecen de naturaleza mercantil. 
rial, le impone el ordenamiento, sean éstas de carácter mercantil, laboral, fiscal, etc. Su condición de actividad empresarial supone que descartemos, como titulares de la misma, las entidades jurídicas que no gocen de dicha consideración, tales como, sociedades civiles, asociaciones y entidades no lucrativas, organizaciones no gubernamentales, fundaciones, comunidades de bienes, etc. Como actividad empresarial libre (Art. $38 \mathrm{CE}$ ), su titularidad puede corresponder tanto a una entidad privada, como pública o de carácter mixto, respetando, en cualquier caso, los principios propios de la libre competencia ${ }^{6}$. Por otra parte, se trata de una actividad empresarial turística, lo cual implica la aplicación del estatuto de empresa turística, entendiendo por tal el conjunto de disposiciones legales y reglamentarias promulgadas para ordenar de forma específica las empresas que se dedican a la prestación de servicios turísticos, y, particularmente, su sujeción a la potestad sancionadora que detenta la Administración en materia turística. Por lo demás, es una actividad reglamentada, por cuanto la Ley de Turismo y los reglamentos de desarrollo establecen la parte fundamental del régimen jurídico-administrativo de esta actividad empresarial, como actividad propiamente turística. Su carácter reglamentado implica la sujeción a la obtención de autorización previa, bajo la denominación de título-licencia, como se verá más adelante. Se requiere, además, la existencia de profesionalidad y habitualidad, condiciones predicables de cualquier actividad empresarial, pues la organización esporádica, carente de fin lucrativo, de actividades de mediación u organización de servicios turísticos no implica la transformación del organizador en empresario o empresa de intermediación. En función de las características y condiciones concurrentes, en cada caso, estas actividades podrán ser consideradas libres (permitidas) o serán actuaciones que requieran legalmente la intervención profesional de una empresa de intermediación turística o se tratará, finalmente, de una actividad clandestina sancionable ${ }^{7}$. Finalmente, la actividad material en que consiste objetivamente las labores propias de la intermediación turística es la mediación, comercialización y organización de servicios turísticos. Si la actividad que dio origen a este tipo de empresas fue la de mediación entre ofertantes y deman-

\footnotetext{
${ }^{6}$ Vid. TENA PIAZUELO, V., "El sector público económico: la empresa pública", en BERMEJO VERA, J., Derecho Administrativo. Parte especial. 5ํㅡㄹ. Ed. Cívitas, Madrid, 2001, pp. 955-956.

${ }^{7}$ Una de las funciones que asumen los reglamentos de agencias de viajes es la de delimitar la actividad de las agencias de viajes, determinando en qué supuestos es preceptiva su intervención en la organización y/o ejecución de viajes; en qué condiciones otros organismos y entidades pueden ser autorizados para organizar viajes, sin fin lucrativo o comercial, para sus miembros o asociados, y, finalmente, los supuestos de actividades clandestinas o de intrusismo profesional que han de ser objeto de sanción.
} 
dantes de servicios turísticos, con el transcurso del tiempo se ha ido ampliado su campo de actuación adicionando al anterior, la organización de servicios turísticos y su comercialización, pudiendo utilizar para ello medios propios (alojamientos, transportes, etc.), en los que no interviene como mediadora de otras empresas.

\section{TIPOS DE EMPRESAS DEDICADAS A LA INTERMEDIACIÓN TURÍSTICA}

De nuevo en este punto, la ordenación autonómica ofrece posturas dispares. Por una parte, un conjunto de Leyes de Turismo, según se ha indicado, únicamente contempla, como empresas de intermediación turística a las agencias de viajes ${ }^{8}$. Frente a ellas, otras Leyes enumeran diferentes opciones, previendo, incluso, una posible ampliación por vía reglamentaria. En este segundo grupo destacan las Leyes de Andalucía, Aragón, Principado de Asturias y La Rioja, que relacionan junto a las agencias de viajes, las centrales de reservas, además de otras empresas de intermediación "que se determinen reglamentariamente". Por su parte, la Ley de Turismo de Navarra incluye a agencias de viajes; agrupaciones de empresas turísticas para la comercialización común de sus ofertas; centrales de reservas; organizadores profesionales de congresos; y, aquellas que tengan por objeto la comercialización, mediación, organización de servicios turísticos e información turística, cuando no constituyan el objeto propio de la agencia de viajes y reglamentariamente se clasifiquen como tales. También la Ley de Castilla-La Mancha ofrece una relación abierta, incluyendo a agencias de viajes; a las empresas que tengan por objeto la comercialización, intermediación, organización y prestación de servicios turísticos que no constituyan objeto propio de las agencias de viajes y reglamentariamente se califiquen como turísticas; y, finalmente, las agrupaciones de empresas destinadas a la comercialización común de ofertas o a la centralización de reservas y reglamentariamente se califiquen como turísticas. En otros casos, se considera como empresa de intermediación únicamente a la agencia de viajes, pero se prevé una ulterior ampliación por vía reglamentaria, como ocurre en Cataluña y Castilla y León ${ }^{9}$. Por último, la Ley de Turismo de Ca-

\footnotetext{
${ }^{8}$ Esta posición es adoptada por las Leyes de Turismo de Baleares, Comunidad de Madrid, Extremadura, Galicia, Región de Murcia, País Vasco y Comunidad de Valencia.

${ }^{9}$ Este último expresado de forma poco clara: "Se establecerán reglamentariamente las clasificaciones y requisitos exigibles a las empresas de intermediación turística" (Art. 28,4).
} 
narias que se refiere, de forma más genérica a agencias de viajes, operadores turísticos y "demás empresas de intermediación turística", sin mayor precisión. Únicamente la Ley cántabra opta por una relación cerrada, resultando la más detallada al incluir a agencias de viajes; organizadores profesionales de congresos; centrales de reservas; empresas de comercialización turística; empresas especializadas en cursos extranjeros; empresas de turismo activo; y empresas de actividades y servicios complementarios.

El desarrollo reglamentario de las previsiones legales respecto a la tipología de empresas de intermediación turística resulta igualmente dispar, pues en algunos casos, se trata de disposiciones aún no adaptadas plenamente a la respectiva Ley de Turismo. De esta forma el régimen jurídico de las empresas de intermediación turística, actualmente vigente, reduce la tipología de la siguiente forma: únicamente Andalucía y La Rioja cuentan con desarrollo reglamentario para las agencias de viajes, centrales de reservas y organizadores profesionales de congresos; las restantes Comunidades Autónomas sólo han regulado la actividad de las agencias de viajes ${ }^{10}$.

\section{REGULACIÓN LEGAL DE LA INTERMEDIACIÓN TURÍSTICA}

La actividad turística, como manifestación social y de masas, es una actividad relativamente reciente, que los investigadores del turismo sitúan a mediados del siglo XX, tras la Segunda Guerra Mundial ${ }^{11}$, apareciendo vinculado a diversas circunstancias concurrentes, tales como, la mejora de los medios de comunicación y trasporte, el incremento del nivel de vida de la población, las mejoras sociales de los trabajadores y, particularmente, la introducción de las vacaciones anuales retribuidas, etc. Entre las circunstancias que cooperan

${ }^{10}$ Incluyendo el Reglamento estatal de 1988, aplicable en País Vasco, Ceuta y Melilla.

11 ÁLVAREZ SOUSA, A., tras comentar los orígenes del turismo, afirma que "hay que esperar a la segunda mitad del siglo XX para que las repercusiones del desarrollo técnico y las consecuciones sociales de los trabajadores posibiliten la aparición del fenómeno «turismo de masas»", en El ocio turístico en las sociedades industriales avanzadas, Bosch, Barcelona, 1994, p. 30. Para DÍAZ ÁLVAREZ, J.R., "la modificación profunda del carácter elitista del turismo decimonónico no se alcanzará hasta las primeras décadas del siglo actual (XX), cuando comienza la socialización del fenómeno, pero el despegue inicial sólo se produce después de que entre en vigor la legislación social de las vacaciones pagadas, acordadas como principio en una Convención de la Organización Internacional del Trabajo", en Geografía del Turismo, Síntesis, Madrid, 1988, p. 19. 
a un rápido desarrollo de la actividad turística y a su generalización destaca la creación y progresiva implantación de las agencias de viajes ${ }^{12}$. No es de extrañar, por tanto, que Thomas Cook, fundador de la primera agencia de viajes del mundo, Thomas Cook and Son, sea considerado el padre del turismo ${ }^{13}$. Por su parte, el desarrollo de la actividad turística en España determina que durante más de 30 años la actividad empresarial de intermediación carezca de normativa específica, de tal forma que la primera agencia de viajes, Viajes Marsans, se constituye en 1910, no siendo aprobada la normativa de agencias de viajes hasta 1942.

Como acabamos de indicar, la primera disposición reguladora de las Agencias de Viajes se aprueba por Decreto de 19 de febrero de 1942, estableciendo dos cuestiones de indudable trascendencia, por una parte, convierte la actividad de intermediación turística en actividad reglamentada, es decir, en actividad empresarial sometida, en parte, al Derecho Administrativo; y, en segundo lugar, reconoce aunque de forma aún embrionaria la facultad de intervención y control de la Administración pública sobre una actividad empresarial hasta entonces ajena a controles administrativos específicos. Por lo demás, el Decreto regula los fundamentos del régimen jurídico-administrativo de la intermediación turística que se mantendrán, con las modificaciones oportunas, hasta la actualidad. De esta forma, enumera las actividades propias de estas empresas, reservándolas en exclusividad; prohíbe el uso de la palabra «turismo» como parte del título o subtítulo, sin contar con la autorización previa de la Administración; efectúa la primera clasificación administrativa de las agencias de viajes, en agencias del grupo A y agencias del grupo $\mathrm{B}^{14}$; establece la reserva

12 RECALDE CASTELLS, R., manifiesta, en este sentido, que "El turismo realizado de forma individualizada y personal en el que todos los elementos del viaje son programados por el propio turista posee en la actualidad una significación muy secundaria". Vid. "Las agencias de viajes", op. cit., p. 158.

${ }^{13}$ Sobre las iniciativas empresariales de Thomas Cook, consideradas como las primeras actividades propiamente turísticas del mundo, puede consultarse, entre otros, a FERNÁNDEZ FÚSTER, L., Introducción a la Teoría y Técnica del Turismo, Alianza Editorial, Madrid, 1985, pp. 5052. En la historia de las agencias de viajes es imprescindible citar, además a Henry Wells y Willians Fargo que crearon la compañía Americam Express que puso en funcionamiento los cheques de viajes, convirtiéndose más adelante en una de las agencias de viajes más importantes del mundo. Vid. ALBERT PIÑOLE, I., BAYÓN MARINÉ, F., y CERRA CULEBRAS, J., "Agencias de viajes", en 50 años de turismo español. Un análisis histórico y estructural, Ceura, Madrid, 1999, p. 815.

${ }^{14}$ Las agencias de viajes pertenecientes al grupo A debían cumplir los siguientes requisitos: ser depositarias y expendedoras de billetaje de la Unión Internacional o del billetaje de tres naciones 
de uso del título de «agencia de viajes»; somete a las agencias a la previa obtención del título-licencia por parte de la Administración, determinado los requisitos para ello; y detalla las funciones que corresponden a la Administración respecto a las agencias de viajes: concesión del título-licencia; lucha contra las actividades clandestinas; control sobre la reposición de la fianza; intervención y regulación de las agencias de viajes y control de la adaptación de las agencias existentes a los preceptos del propio Decreto.

La siguiente reglamentación de agencias de viajes, dictada en sustitución de la vigente desde 1942, se aprueba por Decreto 735/1962, de 29 de marzo, desarrollado por Orden Ministerial de 26 de febrero de 1963. Esta normativa incorpora un concepto detallado de agencia de viajes como "las personas naturales o jurídicas que, en posesión del título correspondiente otorgado por el Ministerio de Información y Turismo, se dedican profesionalmente al ejercicio de las actividades mercantiles de mediación dirigidas a poner los bienes y servicios turísticos a disposición de quienes deseen utilizarlos", manteniendo su clasificación en grupo A y grupo B, aunque imponiendo como criterio su autonomía y el ámbito y extensión de sus actividades. En orden a sus relaciones con la Administración turística, el reglamento regula detalladamente los requisitos para la obtención del título-licencia y las principales obligaciones de las agencias de viajes, respecto a la fianza; el nombramiento de representante personal; el ejercicio de las actividades de intermediación y organización; el delegado personal de agencias extranjeras; etc. Finalmente destaca la concreción de potestades que corresponden a la Administración, que incluye la autorizatoria, de fiscalización e intervención administrativa, sancionadora y de protección frente al intrusismo profesional. La Orden Ministerial prevé que las agencias del grupo A puedan especializarse como agencias de viajes mayoristas, remitiéndose a la correspondiente normativa complementaria (Art. 5), que se aprueba por Orden Ministerial de 12 de abril de 1966, siendo aplicable únicamente a las agencias del grupo A que actúen exclusivamente como mayoristas, es decir, que se dediquen a programar y organizar viajes y servicios turísticos complejos para su ofrecimiento a las agencias de prestación directa al público.

europeas; ser concesionarias para la venta de billetes de cupones combinados de la Red Nacional de los Ferrocarriles Españoles (RENFE); ser concesionarias para la venta de billetes de las Compañías Aéreas Españolas; estar autorizadas para la venta de pasajes de las principales Compañías de Navegación españolas y tener concertados los seguros de responsabilidad civil para cubrir los riesgos de los viajes. Las restantes agencias pertenecían al grupo B, que servían de intermediarias entre las agencias del grupo A y el público. 
En esta época de gran desarrollo del turismo de masas en España, se dictarán tres disposiciones de singular relevancia para la ordenación de las empresas turísticas: la Ley de Competencias en Materia de Turismo, el subsiguiente Estatuto Ordenador de las Empresas y de las Actividades Turísticas Privadas y, finalmente, el Estatuto de Directores de Empresas Turísticas.

La Ley 48/1963, de 8 de julio, de Competencias en Materia de Turismo, lejos de modificar el régimen jurídico de las agencias de viajes y demás empresas turísticas, se limita a fijar las competencias del Ministerio de Información y Turismo en materia de turismo, particularmente, en relación con las empresas y actividades turísticas. Conforme determina la Ley corresponde al Ministerio respecto a las empresas de intermediación turística, su ordenación y vigilancia; el directo ejercicio de las actividades propias de las agencias de viajes en defecto o para estímulo y fomento de la iniciativa privada; la ordenación y vigilancia de dichas empresas y el ejercicio de la potestad sancionadora, en relación con las materias reguladas por la Ley.

Por su parte, el Estatuto Ordenador de las Empresas y de las Actividades Turística Privadas ${ }^{15}$, dictado en desarrollo de la Ley, sí afecta a la ordenación jurídica de las empresas de intermediación turística, pues su objetivo era establecer la regulación común al conjunto de empresas turísticas, de forma que dichas materias no se reiterasen innecesariamente en cada normativa específica. La incidencia del Estatuto Ordenador, en la regulación de las agencias de viajes se centrará en los siguientes aspectos: a) Detalla las competencias que asume la Administración, entre las que se incluye, la regulación de su constitución y funcionamiento; la autorización de apertura y cierre de las agencias y sus sucursales; la determinación de su clase y categoría; la inspección; la vigilancia del cumplimiento de la normativa sobre precios; la adopción de medidas de fomento; la resolución de reclamaciones de los usuarios; el ejercicio de la potestad sancionadora y, finalmente, la resolución de recursos administrativos; b) Declara libre el ejercicio de las actividades de intermediación turística, sin perjuicio del cumplimiento de las disposiciones reglamentarias, admitiendo la libre transmisión de la empresa, previa comunicación a la Administración y publicación de un anuncio en dos diarios de máxima tirada de la provincia; c) Incluye limitaciones en la denominación de la agencia, prohibiendo el uso de los términos «turismo» o «turístico», y los idiomas extranjeros, salvo los referidos a apellidos de reconocido prestigio internacional en las actividades turísticas o a accidentes geo-

\footnotetext{
${ }^{15}$ Aprobado por Decreto 231/1965, de 14 de enero.
} 
gráficos; d) Considera las agencias de viajes como establecimientos públicos, siendo libre el acceso a sus instalaciones, aunque pueden autorizarse determinadas limitaciones; e) Por último, relaciona las obligaciones de las empresas y los clientes, así como las responsabilidades y sanciones que pudieran imponerse a aquellas. Por lo demás, el Estatuto Ordenador implica la expresa derogación de los arts. 70 a 74 de la Orden Ministerial de 1963 referida a la materia sancionadora, que pasa a ser regulada por el propio Estatuto.

Destaca, por otra parte, la aplicación directa a las empresas de intermediación turística del Estatuto de Directores de Empresas Turísticas, aprobado por Orden Ministerial de 10 de junio de 1967. Esta disposición impone la existencia de un director, entre otros supuestos, "en las agencias de viajes y en sus sucursales, cuando estas últimas estuvieren situadas en localidad distinta de aquella en que radique la oficina principal. Si existieran varias sucursales en una misma localidad bastará un solo director para todas ellas" (Art. 1,1,e). Para ejercer el cargo de director de una agencia de viajes, a partir de la entrada en vigor del mencionado Estatuto de Directores, será preciso, bien estar en posesión del título de Técnico de Empresas Turísticas expedido o convalidado por la Administración del Estado, bien haber prestado servicios profesionales en las empresas que menciona el Estatuto durante un periodo mínimo de doce años, cuatro de los cuales habrían de ser desempeñando cargos técnicos de especial responsabilidad, además de superar los cursos o exámenes de aptitud convocados al efecto por la propia Administración Turística (Art. 2).

La tercera reglamentación de agencias de viajes se aprueba por Decreto 1524/1973, de 7 de junio, desarrollado por Orden Ministerial de 9 de agosto de 1974. Como aspectos novedosos incorporados por esta normativa destacan la obligación de que las agencias de viajes se constituyan en sociedad mercantil ${ }^{16}$; el beneplácito para que las agencias puedan prestar servicios a los usuarios turísticos utilizando sus propios medios (de transportes, alojamientos turísticos, restaurantes y cafeterías, etc.); la incorporación de la clasificación tripartita entre agencias mayoristas, agencias del grupo A y agencias del grupo $\mathrm{B}$, si bien limitando de forma considerable el campo de actuación de estas últimas $^{17}$; determinación de que las entidades, organismos y particulares que

\footnotetext{
${ }^{16}$ En el anterior reglamento esta obligación se imponía únicamente a las agencias de viajes clasificadas en el grupo A.

17 "Han de limitar la oferta de sus servicios a la provincia donde está domiciliada (...). No podrán establecer sucursales ni dependencias de ninguna clase ni representar a agencias de viajes extranjeras, ni programar, organizar o realizar servicios combinados y viajes a forfait para su ofrecimiento o venta a otras agencias" (Art. 4,c).
} 
promuevan excursiones o viajes colectivos, como servicio combinado o «a forfait», deban encomendarlo a una agencia de viajes, salvo que sean particulares o entidades no mercantiles que cuenten con autorización previa de la Administración, y realicen la actividad de forma esporádica y no lucrativa; y, finalmente, contempla una ordenación restrictiva respecto a las actividades en España de agencias de viajes extranjeras.

La última reglamentación estatal sobre agencias de viajes se contiene, finalmente, en el Real Decreto 271/1988, de 25 de marzo, desarrollado por Orden Ministerial de 14 de abril de 1988, y es fruto de la Conferencia Sectorial de Turismo celebrada el 7 de octubre de 1987, con objeto de formular una normativa común en toda España. Las modificaciones que introduce en el régimen jurídico de las agencias de viajes esta normativa resultan significativas. Así, exige la constitución de una sociedad anónima o limitada, excluyendo, cualquier otro tipo de personificación, y fija un capital social mínimo (en función de la clase de agencia) totalmente suscrito y desembolsado ${ }^{18}$; introduce la clasificación en agencias mayoristas, minoristas y mayoristas-minoristas; determina que el otorgamiento del título-licencia lo efectúe la Administración competente en función de la sede o domicilio legal de la empresa; regula las condiciones de la fianza, que podrá ser individual o colectiva y la preceptiva contratación de una póliza de seguros por responsabilidad civil de la explotación del negocio, responsabilidad civil indirecta o subsidiaria y responsabilidad por daños patrimoniales primarios ${ }^{19}$; exige que el director de la agencia cumpla los requisitos que se establecen en el nuevo Estatuto de Directores de Establecimientos de Empresas Turísticas ${ }^{20}$; sustituye la Comisión Mixta de Vigilancia por las Comisiones Arbitrales de Agencias de Viajes ${ }^{21}$; y, finalmente,

${ }^{18}$ La cuantía del capital social se establecía en 10.000.000 ptas. para las agencias minoristas; 20.000.000 ptas. para las mayoristas y, finalmente, 30.000.000 para las agencias mayoristas-minoristas.

19 Vid., entre otros, CONTRERAS DE LA ROSA, I., "Responsabilidad de agencias organizadoras y detallistas de viajes combinados", en Derecho y Turismo, III Jornadas de Derecho Turístico, Consejería de Turismo y Deporte. Junta de Andalucía, Sevilla, 2000, pp. 203-209 y BOLDÓ RODÁ, C., "Algunas notas acerca de la responsabilidad de las agencias de viajes", en Revista de Derecho Mercantil, núm. 240, 2001, pp. 749-775. 1967.

20 Aprobado por Orden Ministerial de 11 de agosto de 1972, en sustitución del anterior de

${ }^{21}$ La Comisión Mixta de Vigilancia de las Agencias de Viajes había sufrido anteriormente una reestructuración aprobada por Orden Ministerial de 8 de mayo de 1978. 
amplía las posibilidades de actuación de las agencias de viajes extranjeras puesto que permite que encomienden su representación a una o varias agencias españolas, que contraten directamente servicios turísticos en España o que establezcan delegaciones, previa la correspondiente autorización administrativa.

Asumida la competencia de ordenación del turismo por las Comunidades Autónomas éstas inician su actividad normativa aprobando las disposiciones aplicables a las distintas actividades turísticas, entre ellas las correspondientes a la intermediación turística. Algunas Comunidades Autónomas aprueban su reglamentación de agencias de viajes incluso antes que la normativa estatal de 1988; otras, en cambio, lo harán posteriormente, procurando mantener los acuerdos adoptados en la citada Conferencia Sectorial de Turismo de 1987. En muchos casos se han producido modificaciones ulteriores o ha sido sustituida la normativa primitiva por una más moderna, especialmente para adaptarla a la Ley de Viajes Combinados de 1995. Esta Ley, sin embargo, no afectó de forma significativa al régimen jurídico-administrativo de las empresas de intermediación turística, pues su finalidad fue la regulación del viaje combinado y, por tanto, los derechos y obligaciones de las partes contratantes, para dotar de una mayor protección al usuario turístico, regulando, por tanto, cuestiones esencialmente jurídico-mercantiles. Sin embargo, destacaremos tres aspectos regulados en la Ley, con relevantes consecuencias jurídico-administrativas: La fianza como garantía de responsabilidad contractual (cuyo control corresponderá a la propia Administración); la necesidad de que organizador y detallista se constituyan en agencias de viajes; $y$, por último, la remisión a la potestad sancionadora de la Administración para corregir los incumplimientos de la propia Ley de Viajes Combinados. Por tanto, esta Ley mantuvo intactas las funciones esenciales de la Administración con relación a la constitución y funcionamiento de las agencias de viajes y demás empresas de intermediación turística.

Por su parte, del estudio de la compleja normativa autonómica en la materia, particularmente, de los reglamentos que regulan la constitución y funcionamiento de las agencias de viajes y demás empresas de intermediación ${ }^{22}$,

${ }^{22}$ La reglamentación autonómica en materia de agencias de viajes, queda configurada de la siguiente forma: Decreto 301/2002, de 17 de diciembre, de Agencias de Viajes y Centrales de Reservas de Andalucía; Decreto 51/1998, de 24 de febrero, Reglamento de Agencias de Viajes de Aragón. Este Decreto sustituyó al anterior Decreto 184/1988, de 5 de diciembre; Decreto 60/1997, de 7 de mayo, Reglamento de Agencias de Viajes de Baleares. Este Decreto deroga al Decreto 9/1988, de 11 de febrero y al Decreto 43/1996, de 5 de abril; Decreto 135/2000, de 10 de julio, Regulación de las Agen- 
deducimos las siguientes conclusiones: a) En relación con la tipología de empresas, exceptuando la normativa andaluza y la riojana que incluyen agencias de viajes, centrales de reservas y organizadores profesionales de congresos, en las restantes Comunidades Autónomas, las únicas empresas de intermediación reconocidas y reglamentadas son las agencias de viajes; b) Las agencias de viajes son consideradas empresas turísticas dedicadas en exclusividad a actividades de mediación, comercialización y prestación de servicios turísticos; c) Pueden utilizar medios propios para la prestación de servicios turísticos a los usuarios, estableciéndose, en estos casos, responsabilidad directa, no subsidiaria; d) Su actividad queda sometida a la previa concesión del título-licencia que habilita para el ejercicio empresarial de la actividad de agencia de viajes. La concesión del título-licencia corresponde a la Administración de la Comunidad Autónoma en la que tenga su domicilio o sede central ${ }^{23}$; e) Respecto a la titularidad de la empresa, en unos casos se permite la concurrencia tanto de personas físicas, como jurídicas y, en otros, en cambio, sólo pueden obtener el título-licencia las sociedades mercantiles, anónimas o limitadas; f) Se asigna a las agencias de viajes un conjunto de actividades propias, que la califican legal-

cias de Viajes en Canarias. Anteriormente existieron dos reglamentaciones de agencias de viajes: la primera aprobada por Decreto 231/1987, de 18 de diciembre; la segunda, por Decreto 176/1997, de 24 de julio; Decreto 50/1990, de 3 de septiembre, de Ordenación Turística de las Agencias de Viajes de Cantabria; Decreto 25/2001, de 25 de enero, Reglamento de Agencias de Viajes de Castilla y León. Sustituye al anterior Decreto 61/1990, de 19 de abril; Decreto 2/1988, de 12 de enero, de Ordenación de las Agencias de Viaje de Castilla-La Mancha; Decreto 168/1994, de 30 de mayo, Reglamento de Agencias de Viajes de Cataluña. El reglamento original se aprobó por Decreto 45/1988, de 13 de enero; Decreto 119/1998, de 6 de octubre, Reglamento de Agencias de Viajes de Extremadura. Sustituye al anterior Decreto 82/1987, de 28 de diciembre; Decreto 42/2001, de 1 de febrero, por el que se refunde la normativa de Agencias de Viajes, Guías de Turismo Especializado y Turismo Activo de Galicia. Ha sustituido por refundición al Decreto 155/1989, de 22 de junio; Decreto 99/1996, de 27 de Junio, Reglamento de Agencias de Viajes de la Comunidad de Madrid. Modificado por Decreto 214/2000, de 21 de septiembre. Sustituye al Decreto 216/1987, de 28 de diciembre y a la Orden de desarrollo 3/1988, de 26 de febrero; Decreto Foral 141/1988, de 4 de mayo, Reglamento de Agencias de Viajes de Navarra; Decreto 31/1988, de 18 de febrero, de Ordenación de las Agencias de Viajes del Principado de Asturias; Decreto 115/1987, de 24 de diciembre, Reglamento de Agencias de Viajes de la Región de Murcia; Decreto 111/2003, de 10 de octubre, aprueba el Reglamento de desarrollo de la Ley 2/2001, de 31 de Mayo, de Turismo de La Rioja. Anteriormente en La Rioja hubo dos reglamentaciones de agencias de viajes; la primera se aprobó por Decreto 8/1988, de 6 de mayo; la segunda por Decreto 35/1997, de 27 de junio; Decreto 20/1997, de 11 de febrero, Reglamento de Agencias de Viajes de la Comunidad Valenciana. Sustituye al anterior Decreto 58/1988, de 25 de abril, modificado parcialmente por el Decreto 65/1990, de 26 de abril.

23 Únicamente las agencias de viajes radicadas en el País Vasco, Ceuta y Melilla siguen solicitando y obteniendo, en su caso, el título-licencia de la Administración General del Estado. 
mente como tales, y que realizan en exclusividad, sin perjuicio de la facultad que ostentan las empresas turísticas para contratar sus servicios directamente con los usuarios; g) Las agencias de viajes son clasificadas de forma preceptiva en mayoristas, minoristas y mayoristas-minoristas ${ }^{24}$; h) Se regulan los aspectos fundamentales del procedimiento administrativo para la obtención del título-licencia de agencia de viajes, en particular, los documentos que habrán de acompañar a la solicitud, plazo de resolución y sentido del silencio administrativo; i) Se determinan las obligaciones económicas de las agencias de viajes, como medio de garantía frente a los usuarios, centradas, en la exigencia de un capital social mínimo totalmente desembolsado, en su caso ${ }^{25}$; el establecimiento y mantenimiento de una fianza y la contratación permanente de una póliza de seguros; j) Obligación de inscribir en la Oficina Española de Patentes y Marcas el rótulo y nombre comercial de la agencia; k) Obligación de situar a la entrada del establecimiento y en lugar visible, la placa-distintivo normalizada en la que figure el código de identificación de la agencia y su grupo; y, l) Constitución y funcionamiento del sistema de arbitraje para la resolución de conflictos entre usuarios y agencias de viajes (Junta Arbitral de Consumo, Comisión Arbitral de Agencias de Viajes, etc.).

En resumen, el régimen jurídico-administrativo de la intermediación turística impone una permanente vinculación, de carácter especial, entre las empresas dedicadas a dicha actividad y la Administración que abarca: otorgamiento

${ }^{24}$ La Ley de Turismo de Aragón adopta una nomenclatura peculiar en la clasificación tripartita: mayoristas u organizadores; minoristas o detallistas y mayoristas-minoristas u organizadoresdetallistas (Art. 46), mientras que los reglamentos de agencias de viajes de Baleares y Cataluña optan por la clasificación de mayoristas, detallistas y mayoristas-detallistas. En este sentido, debemos recordar que la Ley de Viajes Combinados, en consonancia con la Directiva Comunitaria de la que trae origen y la terminología propia de otros países comunitarios denomina a los intermediarios turísticos como organizador y detallista. En correspondencia con la tipología de agencias de viajes, el organizador sólo puede ser una agencia mayorista-minorista al tener la facultad de organizar viajes combinados y venderlos directamente o por medio de un detallista (Art. 2,2 Ley de Viajes Combinados -LVC-), mientras que el detallista puede ser tanto una agencia minorista como una mayorista-minorista, pues ambas tienen la facultad de vender el viaje combinado propuesto por un organizador (Art. 2,3 LVC). Vid. GÓMEZ CALERO, J., Régimen jurídico del contrato de viaje combinado, Dykinson, Madrid, 1994, p. 47.

${ }^{25}$ La imposición de un capital social mínimo, superior al que con carácter general exige la legislación mercantil (Ley de Sociedades Anónimas o de Sociedades de Responsabilidad Limitada), se incluye en los reglamentos de agencias de viajes de las Comunidades Autónomas de Baleares, Canarias, Cantabria, Cataluña, Castilla-La Mancha, Galicia, Navarra, Principado de Asturias y Región de Murcia. 
del título-licencia; inscripción en el Registro de empresas turísticas; autorización de apertura de sucursales; facultad de inspección; potestad sancionadora; anotación de la información facilitada por la empresa en relación con: nombramiento y cese de director, modificaciones sustanciales de los estatutos sociales, cambio de domicilio, etc.; facultad de revocación del título-licencia por incumplimiento de las condiciones que se tuvieron en cuenta para su otorgamiento; autorizar la organización y/o realización de viajes por entidades que carezcan de la consideración de agencia de viajes; control sobre la apertura de sucursales de agencias de viajes pertenecientes a otras Comunidades Autónomas o a agencias de viajes extranjeras; autorizar la utilización de locales que no cumplan el principio de exclusividad; lucha contra el intrusismo profesional; intervención en los mecanismos de resolución arbitral de reclamaciones; etc. Este conjunto de relaciones, como parte especial del Derecho Administrativo, se integra en la competencia autonómica de promoción y ordenación del turismo (Art. 148,1,18을 $\mathrm{CE}$ ), por lo que su régimen jurídico esencial se integra por la Ley autonómica de Turismo y el correspondiente reglamento de desarrollo en relación con las empresas de intermediación turística ${ }^{26}$.

No obstante, los reglamentos autonómicos de agencias de viajes incorporan una serie de artículos dedicados a la ordenación del «ejercicio de las actividades de las agencias de viajes», regulando dos cuestiones relativas al funcionamiento mercantil de la agencia de viajes. Por una parte, la ordenación de la oferta, contratación y ejecución de los viajes combinados, aspectos regulados por la Ley 21/1995, de 6 de julio, de Viajes Combinados. Los reglamentos aprobados en fecha posterior a la entrada en vigor de dicha Ley, se remiten a ella para tales cuestiones ${ }^{27}$, en cambio, los promulgados en fecha anterior y no adaptados mediante ulterior reforma contienen una regulación propia referida a la información, contratación y ejecución de los llamados «paquetes turísticos», que debemos entender derogada y sustituida por el contenido de la citada Ley $21 / 1995^{28}$. El reglamento de Agencias de Viajes de Cataluña opta, en

\footnotetext{
${ }^{26}$ Sólo la Comunidad Autónoma de La Rioja ha optado por abordar el desarrollo de la Ley de Turismo mediante una única disposición reglamentaria, que complementa a la Ley en toda su extensión.

${ }^{27}$ En esta situación se encuentran actualmente un total de doce disposiciones reglamentarias correspondientes a las Comunidades Autónomas de Andalucía, Aragón, Baleares, Canarias, Castilla y León, Extremadura, Galicia, Comunidad de Madrid, Región de Murcia, La Rioja y Comunidad de Valencia.

${ }^{28}$ Los Reglamentos no adaptados a la Ley de Viajes Combinados son los correspondientes a Cantabria, Castilla-La Mancha, Navarra y Principado de Asturias. La LT Castilla-La Mancha efectúa una referencia en su articulado a la Ley de Viajes Combinados pero únicamente en el ámbito sancionador (Art. 64)
} 
cambio, por insertar la normativa sobre viajes combinados de la propia Directiva Comunitaria en su articulado, excediéndose, a nuestro parecer, en su competencia de ordenación del turismo y contraviniendo la competencia estatal sobre legislación civil y mercantil. Tampoco consideramos adecuada la postura adoptada por el reglamento de desarrollo de la Ley de Turismo de La Rioja, al establecer el carácter supletorio de la Ley de Viajes Combinados en la regulación de los precios, depósito y anulación de los viajes combinados (Art. 170,1), pues consideramos que la ordenación de la información, contratación y ejecución de un viaje combinado queda establecida en la Ley 21/1995 de Viajes Combinados, dictada por el Estado en ejercicio de su competencia sobre la legislación mercantil (Art. 149,1,6ㅜ CE), debiendo los reglamentos autonómicos respetar el contenido de dicha Ley en tales aspectos. Por otra parte, en relación con los restantes servicios que prestan las agencias, como «servicios sueltos» $\mathrm{y}$ «excursiones de un día», los reglamentos autonómicos suelen regular los tipos de contratos entre agencias de viajes y usuarios turísticos; los requisitos para la elaboración de folletos y programas para facilitar información a los usuarios; el contenido de la información que deben facilitar las agencias a los usuarios sobre los servicios contratados; la posibilidad de exigir un depósito, en concepto de señal y anticipo del precio final; las condiciones sobre los precios a percibir por las agencias; los documentos que éstas han de entregar al usuario al perfeccionarse el contrato; las consecuencias del desistimiento anticipado; obligación de la agencia en relación con el cumplimiento del contrato, consecuencias de su incumplimiento y causas eximentes; etc. Entendemos que todos estos aspectos afectan a relaciones jurídico-mercantiles, formando parte de la competencia estatal sobre legislación mercantil, que las Comunidades Autónomas deben respetar, excluyendo, por tanto e su normativa de ordenación turística de las empresas de intermediación las citadas materias.

\section{LA HABILITACIÓN PARA EL EJERCICIO PROFESIONAL DE LA INTERMEDIACIÓN TURÍSTICA}

Como requisito previo a la apertura de una empresa turística, y con independencia de otras autorizaciones impuestas con carácter general, las Leyes de Turismo exigen autorización, clasificación e inscripción en el correspondiente Registro de Turismo, al objeto de salvaguardar los intereses públicos presentes y garantizar la protección de los usuarios y de los recursos turísticos. De esta forma, las empresas de intermediación turística requieren una autorización administrativa turística previa a su instalación e inicio de su actividad mercantil, que adquiere la denominación de título-licencia, otorgada la Admi- 
nistración competente, con independencia de la concurrencia, como hemos indicado, de otras autorizaciones o permisos (licencia de obras, licencia municipal de apertura, etc.) Se trata, pues, de un tipo de autorización industrial «in genere», que "remueve el límite y confiere así la facultad del ejercicio. La emanación del acto de remoción de límites corresponde a la Administración, dado que se trata de una función no política ni de gobierno, sino administrativa" ${ }^{29}$. A diferencia de la concesión, la autorización tiene carácter declarativo, permitiéndose a través de ella, el ejercicio de un derecho preexistente en la esfera jurídica del interesado, previa comprobación del cumplimiento de los requisitos establecidos y de su adecuación al interés público tutelado ${ }^{30}$.

Este título-licencia de agencias de viajes queda regulado, pues, como instrumento administrativo de intervención dirigido a ordenar y, en parte, controlar, el sector empresarial de la intermediación turística. Se trata, por tanto, de un supuesto típico de autorización administrativa, cuyo otorgamiento y revocación, en su caso, corresponde a la Administración competente en la materia. De acuerdo con las diferentes clasificaciones doctrinales sobre los actos de autorización, podemos calificar el título-licencia necesario para el ejercicio de la actividad empresarial de una agencia de viajes como un acto administrativo de autorización de carácter reglado, de funcionamiento, real y simple ${ }^{31}$.

El título-licencia de agencia de viajes es un tipo de autorización reglada pues la Administración sólo ha de comprobar que el solicitante cumple los requisitos establecidos por el ordenamiento para su obtención, sin efectuar apreciación alguna de carácter subjetivo o de oportunidad ${ }^{32}$. Estas autorizaciones no requieren "más que un mero contraste con los requisitos establecidos en la norma debiendo ser expedida si el particular acredita su cumplimiento. (...) En este caso la autorización suele denominarse licencia o incluso homologación”33. En esta línea argumental se expresa el Tribunal Supremo,

${ }^{29}$ VILLAR PALASÍ, J.L., La intervención administrativa en la industria, Instituto de Estudios Políticos, Madrid, 1964, p. 315.

${ }^{30}$ Vid. PAIS RODRÍGUEZ, R. y REBOLLO DELGADO, L., Introducción al Derecho I. Derecho Público, Dykinson, Madrid, 2004, p. 315.

${ }^{31}$ Vid. GARCÍA DE ENTERRÍA, E., y FERNÁNDEZ RODRÍGUEZ, T.R., Curso de Derecho Administrativo, Cívitas, Madrid, 2001, p. 138.

${ }^{32}$ Vid. BLANQUER CRIADO, D., Derecho del Turismo, Tirant lo Blanch, Valencia, 1999, pp. 315-316.

${ }^{33}$ VILLAR EZCURRA, J.L., Derecho Administrativo Especial, Cívitas, Madrid, 1999, p. 84. 
afirmando que: "La Jurisprudencia utiliza, inicialmente, un concepto de autorización que se ajusta a la noción clásica de acto administrativo que permite a una persona el ejercicio de un derecho o facultad que le corresponde, previa valoración de la legalidad de tal ejercicio en relación con el interés específico que el sujeto autorizante debe tutelar. Y desde este punto de vista tradicional, la autorización administrativa, en cuanto acto de control preventivo y de carácter meramente declarativo que no transfiere facultades sino que remueve límites a su ejercicio, ha de ser otorgada o denegada por la Administración con observancia de la más estricta legalidad"34.

El carácter reglado del título-licencia de agencia de viajes puede acreditarse analizando los documentos que la Administración ha de considerar para concederlo o denegarlo. Así, la Orden Ministerial de 14 de abril de 1988, exige la presentación de los siguientes documentos: a) Copia legalizada de la escritura de constitución de la sociedad mercantil y de sus estatutos, en la que figure la inscripción en el Registro Mercantil, así como de los poderes de los solicitantes. En la escritura y estatutos de la sociedad debe quedar constancia de la exclusividad respecto al ejercicio de las actividades propias de una agencia de viajes y el capital social mínimo desembolsado; b) Póliza de seguro, por las cantidades y con la cobertura fijadas en la propia Orden; c) Documentos que prueben la disponibilidad de la sede social y de los locales abiertos al público; d) Contrato entre la agencia de viajes y el director; e) Acreditación documental de la constitución de la fianza; f) Certificación que avale la solicitud de inscripción del nombre comercial y rótulo de la agencia en la Oficina Española de Patentes y Marcas; g) Estudio de viabilidad económico-financiera de la empresa proyectada. Los reglamentos autonómicos de agencias de viajes son dictados conforme al modelo estatal, al menos, en cuanto se refiere a los documentos que han de acompañar a la solicitud del título-licencia, que sirven para acreditar el cumplimiento de los requisitos y condiciones que deben reunir las agencias de viaje. Corresponde a la Administración, como actuación previa al otorgamiento del título-licencia, la comprobación, conforme a la documentación aportada, de los requisitos exigidos, referidos al cumplimiento de datos de carácter objetivo, que no permiten graduación o valoración, en su estudio por parte de la Administración: la constitución de la sociedad titular de la agencia; la existencia y amplitud de los poderes otorgados, en su caso, a favor del solicitante; la disponibilidad y características del local o locales; la

34 STS de 18 de noviembre de 2002, referida a la intervención administrativa de centros y establecimientos sanitarios, conforme a la Ley General de Sanidad. 
constitución de la fianza y su cuantía; la contratación de la póliza de seguros y la amplitud de su cobertura; el capital social de la entidad titular, etc.

Únicamente los reglamentos de Agencias de Viajes de Cantabria, CastillaLa Mancha, Galicia, Navarra, Principado de Asturias y Región de Murcia, a semejanza del estatal, incluyen entre los documentos que deben acompañar a la solicitud, el mencionado proyecto de viabilidad económica-financiera de la agencia de viajes. En este punto consideramos, que la Administración no puede denegar el título-licencia aduciendo una valoración negativa de la futura viabilidad de la iniciativa empresarial, puesto ésta es la principal decisión que debe adoptar el empresario ${ }^{35}$, privándose a éste, en caso contrario, de la utilización de un instrumento esencial en el ejercicio de la libertad de empresa, como es su capacidad para decidir sobre la finalidad de su inversión económica $^{36}$. Por esta razón, las restantes Comunidades Autónomas en cuyo reglamento original se preveía la presentación del proyecto de viabilidad económico-financiero, han suprimido este documento en sus nuevas disposiciones ${ }^{37}$.

En algunos casos, la normativa impone la obligación de presentar el contrato entre la agencia y el director o responsable de la misma. Durante la vigencia del Estatuto de Directores de Establecimientos de Empresas Turísti$\operatorname{cas}^{38}$, se exigía que al frente de cada agencia de viajes, y en las sucursales que se encontraran en diferente localidad, un director titulado e inscrito en el Registro de Directores, existente en el Ministerio competente en materia de turismo. Esta limitación ha quedado superada al suprimirse de forma expresa o

35 Para RECALDE CASTELLS, A., "las facultades de la Administración para autorizar o denegar el consentimiento en función de este estudio deben interpretarse, lógicamente, de forma muy restringida. En otro caso se produciría una excesiva injerencia en las facultades de organizar autónomamente la empresa en clara violación de libertades constitucionales y, en particular, de la libertad de empresa". Vid. "Las agencias de viaje”, op. cit., p. 173.

${ }^{36}$ Vid. F.J. 3ํㅗ STC 225/1993, de 8 de julio.

37 Es el caso de las Comunidades Autónomas de Aragón, Baleares, Canarias, Castilla y León, Cataluña, Extremadura, Madrid, La Rioja y Valencia. La normativa andaluza, en cambio, nunca incluyó dicho documento. En las Comunidades Autónomas de Canarias y Baleares, que ya han contado con tres reglamentaciones autonómicas sobre agencias de viaje, el requisito del proyecto de viabilidad económico-financiera ya desapareció en el segundo Reglamento.

38 Aprobado por Orden de 11 de agosto de 1972, en sustitución del anterior Estatuto de Directores de Empresas Turísticas, aprobado por Orden de 10 de junio de 1967. 
tácita en las Leyes de Turismo de las diferentes Comunidades Autónomas. En todo caso, ya sea durante la vigencia del Estatuto de Directores, ya con posterioridad, la función que correspondía a la Administración resultaba estrictamente reglamentada y objetiva, al consistir, por una parte, en comprobar la existencia del contrato y, por otra, en el tiempo en que estuvo vigente el Estatuto de Directores, asegurar la previa inscripción de la persona nombrada por la empresa en el citado Registro, elemento que acreditaba su idoneidad para el cargo ${ }^{39}$, así como la inexistencia de prohibiciones de acceso, considerándose como tal la condena por sentencia firma a pena de inhabilitación o suspensión para el ejercicio profesional, durante el tiempo de cumplimiento de la condena, así como, la sanción con suspensión o baja definitiva en la profesión. En ningún otro caso podía efectuar la Administración una valoración negativa del nombramiento del director de una agencia de viajes que implicara una apreciación de carácter subjetivo.

En otro orden de cosas, debemos destacar la inexistencia en nuestro ordenamiento de una limitación cuantitativa respecto al número de empresas de intermediación turística o de sucursales de las mismas, que puedan instalarse en una misma zona (localidad, provincia, etc.), pues de lo contrario nos encontraríamos ante un servicio público impropio, como ocurre con el servicio de taxi o las farmacias, es decir, ante una actividad privada desde el punto de vista de la persona que presta el servicio, y pública, atendiendo a la función ejercida por la Administración, lo cual exigiría el otorgamiento de la autorización mediante concurso, garantizando así la máxima igualdad y libertad de acceso a la actividad. De igual forma, tampoco se establecen restricciones por la ubicación de la agencia de viajes, justificadas en exigencias vinculadas a la ordenación del territorio o de protección ambiental, a diferencia de otros tipos de establecimientos turísticos en los que la ubicación puede conllevar un impacto territorial y/o ambiental, caso que no ocurre con este tipo de establecimientos que carecen de implicación negativa de carácter territorial o ambiental.

Se trata, por otra parte, de una autorización de funcionamiento o tracto sucesivo, puesto que desde el momento de su otorgamiento se crea una vinculación permanente entre la Administración otorgante y la agencia, que se con-

${ }^{39}$ La inscripción exigía poseer el título de Técnico de Empresas Turísticas, expedido o convalidado por el Ministerio de Información y Turismo, a propuesta de la Escuela Oficial de Turismo, o haber prestado servicios profesionales en uno o varios establecimientos de los que requiriesen director titulado, por un periodo mínimo de 9 años, además de superar unos cursos intensivos organizados al respecto por la Administración (carnet de director). 
creta en la existencia de un conjunto de obligaciones que han de cumplir permanentemente las empresas y una serie de potestades de seguimiento y sanción que detenta la Administración, al objeto de "verificar la adecuación de la actividad particular, en todo momento, a las exigencias del interés público, y, en su caso, la corrección de las trasgresiones que puedan producirse" ${ }^{40}$. En consecuencia, el otorgamiento de la autorización implica, no sólo la remoción del obstáculo existente ab initio para ejercer la actividad, sino también la aplicación de un amplio elenco de derechos, obligaciones y cargas, impuestas por el ordenamiento jurídico a dichas empresas ${ }^{41}$; en definitiva, el otorgamiento del título-licencia implica una "proyección permanente al desarrollo de la actividad, de manera que no se agota la intervención administrativa con el control previo" ${ }^{2}$. Así, las agencias de viajes, una vez obtenido el título-licencia han de llevar a cabo una serie de actuaciones, tales como, el inicio de la actividad en un plazo de tiempo determinado; la formalización de la fianza y la póliza de seguros; el cumplimiento de las previsiones sobre los libros de reclamaciones de inspección; la inscripción definitiva del rótulo y del nombre comercial en la Oficina Española de Patentes y Marcas; etc. Y, por otra parte, durante el desarrollo de su actividad, la empresa habrá de mantener vigentes las condiciones y requisitos que se tuvieron en cuenta para el otorgamiento del títulolicencia, singularmente, las obligaciones económicas establecidas en garantía de los derechos de los usuarios turísticos, tales como, capital social mínimo, fianza, póliza de seguros ${ }^{43}$, etc., así como una relación constante con la Administración turística, que se concreta en la remisión de información relativa a aspectos de especial trascendencia, tales como: modificación de los requisitos o de los documentos incorporados al expediente; utilización de otras marcas comerciales; nombramiento y cese del director o representante de la agencia; apertura de nuevas sucursales; cambios en la denominación de la agencia; traslado de oficinas; instalación de puntos de venta dentro de otras empresas; modificación de los estatutos sociales; cierre de sucursales o puntos de venta;

${ }^{40}$ MORELl OCAÑA, L., Curso de Derecho Administrativo, Aranzadi, Pamplona, 1999, p. 47.

${ }^{41}$ Vid., SUAY RINCÓN, J. y RODRÍGUEZ GONZÁLEZ, M.P., en "Régimen jurídico-administrativo de las agencias de viajes: una visión comparada de la normativa específica en materia de turismo", en BLANQUER CRIADO, D., Turismo. II Congreso Universidad y Empresa, Tirant lo Blanch, Valencia, 2000, p. 455.

${ }^{42}$ Vid. F.J. $5^{\circ}$ STS de 18 de noviembre de 2002.

${ }^{43}$ En general, se concede un plazo de 15 días para comunicar la renovación y/o vigencia de la póliza de seguros y la fianza. 
alteración de la garantía colectiva; etc., y, en general, remitiendo la información y documentación que pueda solicitarle la Administración, en ejercicio de sus funciones, además de someterse y facilitar las labores propias de los servicios de inspección turística.

La Administración, por su parte, detenta una serie de facultades destinadas a garantizar la efectividad de los fines que le encomienda el ordenamiento jurídico: autorizatoria; de registro y certificación; de inspección; de revocación del título-licencia por incumplimiento de las condiciones que se tuvieron en cuenta para su otorgamiento; ejercicio de la potestad sancionadora; requerimiento de datos o información; etc $^{44}$. Particular valor representa la facultad de revocación del título-licencia que conserva la Administración que corrobora la consideración de autorización de funcionamiento, pues tal facultad sólo puede ejercerse si desaparecen las circunstancias que motivaron su otorgamiento, se incumplen los requisitos que se tuvieron en cuenta o sobrevienen nuevas circunstancias que de haber existido en el momento original hubieran justificado su denegación ${ }^{45}$.

Con arreglo a la clasificación de las autorizaciones administrativas que distingue entre autorizaciones personales, reales o mixtas, podemos afirmar el carácter real del título-licencia de agencia de viajes, puesto que los elementos sobre los que se sustenta la misma afectan a condiciones objetivas de la actividad empresarial, no a cualidades personales del solicitante. Los requisitos determinantes del otorgamiento del título-licencia de agencia de viajes son fundamentalmente tres, la capacidad económica del solicitante, el aseguramiento de la responsabilidad y la disponibilidad de determinados elementos en la explotación. La exigencia relativa a la capacidad económica se establece en garantía de las operaciones mercantiles en las que la empresa funciona como intermediaria y se mide por medio del establecimiento de un contrato garantista, como es la fianza. En ocasiones, este condicionante se refuerza con uno

\footnotetext{
${ }^{44}$ En contra de esta interpretación de la autorización de funcionamiento se posiciona PARADA VÁZQUEZ, R., que afirma que se trata de intervenciones administrativas ulteriores a la autorización y fundamentadas en otras potestades administrativas. Vid. Derecho Administrativo I, Parte General, Marcial Pons, Madrid, 2004, p. 383.

45 Así, en la STS de 15 de noviembre de 1968 se confirma la revocación del título-licencia, razonándose que "Sin la constitución de la fianza las agencias de viajes no pueden funcionar y, sin embargo, la resistencia pasiva de la agencia ha permitido, en este caso, que sin haberla constituido, haya seguido funcionando (...)".
} 
adicional: la exigencia de un capital social mínimo para las sociedades mercantiles que, en algún caso, afecta igualmente a los empresarios individuales. En segundo lugar, la garantía de responsabilidad se cumple mediante la firma de pólizas de seguros destinadas a cubrir los riesgos que eventualmente puedan sucederse durante el desarrollo de la relación contractual. Finalmente, el ordenamiento se asegura de la disposición de ciertos instrumentos materiales precisos para la gestión ordinaria de la empresa, tales como, locales comerciales, marca comercial y rótulo, etc. Únicamente, como hemos indicado anteriormente, los reglamentos de algunas Comunidades Autónomas incluyen una referencia explícita al nombramiento del director de la agencia, en consonancia con el Estatuto de Directores de 1972. Consideramos que esta cuestión no afecta al carácter real de la autorización, pues la necesidad de un título académico determinado para acceder a la dirección de determinadas empresas turísticas, ha quedado desplazada por las disposiciones legales y reglamentarias dictadas por las Comunidades Autónomas, que en ningún caso han impuesto condición alguna al respecto.

El carácter real del título-licencia facilita la transmisión del establecimiento, exigiéndose que el nuevo titular cumpla requisitos objetivos similares a los que debía reunir el anterior propietario: mantenimiento de las garantías económicas, póliza de seguros, condiciones físicas de los locales, etc. Por ello, tanto las Leyes de Turismo como los reglamentos de agencias de viajes imponen la obligación de comunicar a la Administración, entre otros aspectos, los cambios de titularidad de la empresa. Al tratarse de una autorización real la transmisión del establecimiento o empresa debe conllevar la de la propia autorización, motivo por el cual el ordenamiento exige la citada comunicación con la finalidad de que la Administración pueda comprobar el mantenimiento de los requisitos que se tuvieron en cuenta al otorgar la licencia original. Únicamente el Reglamento de Agencias de Viajes de Andalucía, aprobado por Decreto 301/2002, determina la intransmisibilidad del título-licencia (Art. 10).

Finalmente, debemos afirmar que el título-licencia de agencia de viajes es una autorización de carácter simple, puesto que con ella la Administración pretende únicamente controlar la actividad, verificar el cumplimiento de los requisitos exigidos legalmente para este tipo de empresas, sin pretender, por tanto, efectuar un encauzamiento u orientación de la actividad que deba llevar a cabo la agencia de viajes, como sucede con las autorizaciones de carácter operativo ${ }^{46}$.

\footnotetext{
${ }^{46}$ Vid. GARCÍA DE ENTERRÍA, E. y FERNÁNDEZ RODRÍGUEZ, T.R., Op. cit., pp. 139-141.
} 


\section{LA PRECEPTIVA INSCRIPCIÓN DE LAS EMPRESAS DE INTER- MEDIACIÓN EN EL REGISTRO ADMINISTRATIVO DE EMPRE- SAS TURÍSTICAS}

La Orden de 26 de febrero de 1963 que aprobó el reglamento regulador de las agencias de viajes ya incluía la existencia de un registro de Agencias de Viajes, siendo la Orden de 20 de noviembre de 1964 la que reguló el Registro de Empresas y Actividades Turísticas, como registro administrativo público y gratuito, dirigido a todas las empresas turísticas. La inscripción de las «empresas turísticas reglamentadas» en el mencionado Registro resultaba preceptiva y la efectuaba de oficio la Administración al otorgar la correspondiente autorización y clasificación, en su caso. Este tipo de inscripción preceptiva se mantendrá en los diferentes reglamentos estatales de agencias de viajes y, posteriormente, en la normativa autonómica, incorporándose, finalmente, al texto de las Leyes de Turismo, que configuran los aspectos esenciales de sus respectivos registros autonómicos ${ }^{47}$.

Aunque la ordenación de los registros de empresas turísticas presenta cierta diversidad, podemos destacar un conjunto de características comunes. Así, en todos los supuestos nos encontramos ante registros públicos, de carácter administrativo, cuya inscripción resulta preceptiva y gratuita. Ésta suele realizarla, como se ha indicado, de oficio la Administración otorgante al conceder la autorización y, en su caso, clasificación de la empresa o establecimiento. Sólo en el caso de la Ley de Turismo de Canarias se produce una separación entre la autorización y la inscripción en el registro, siendo ésta anterior y preceptiva para la obtención de la autorización.

La inscripción registral cumple, por otro lado, fines diversos, tales como, facilitar el ejercicio de las funciones que corresponden a la Administración sobre las empresas turísticas, particularmente las referidas a su control e inspección; suministrar información y seguridad a los usuarios turísticos; conllevar determinadas ventajas para las empresas, en cuanto su inscripción certifi-

\footnotetext{
47 Así, se denomina Registro de Turismo en Andalucía, Aragón, Cataluña y Navarra; Registro de Empresas y Actividades Turísticas en el Principado de Asturias, Galicia y en la Región de Murcia; Registro de Proveedores de Servicios Turísticos en La Rioja; Registro General de Empresas, Actividades y Establecimientos Turísticos en las Islas Baleares y en Canarias; Registro de Empresas Turísticas en el País Vasco y en la Comunidad de Valencia; Registro General de Empresas y Entidades Turísticas en la Comunidad de Madrid; Registro de Empresas y Establecimientos Turísticos en Castilla-La Mancha y en Extremadura; Registro de Empresas, Actividades y Profesiones Turísticas en Castilla y León y Registro General de Empresas Turísticas en Cantabria.
} 
ca el correcto cumplimiento de las prescripciones legales y de calidad y les ofrece un medio de publicidad, permitiendo, además, su incorporación al material y a las actividades de fomento y promoción que realice la Administración y, finalmente, servir como instrumento de certificación de los datos contenidos en el mismo, tales como, la propia autorización, la clase o categoría, la inexistencia de sanciones administrativas, etc.

En relación con el contenido de los registros, pese a su variedad organizativa, puede afirmarse, que bien mediante inscripción, bien mediante anotación, en ellos queda constancia, no sólo de la autorización de funcionamiento y clasificación otorgada por la Administración, mediante la cual se inicia la inscripción registral de una determinada actividad empresarial, sino también de aquellos aspectos que se consideran de mayor relevancia en la vida jurídica de la empresa, tales como, autorización, clasificación y especialización otorgada, en su caso; concesión de dispensa en el cumplimiento de requisitos; cambios de titularidad, domicilio social o denominación de la empresa o establecimientos; sanciones administrativas firmes, hasta su cancelación; concesión de subvenciones y otras ayudas públicas; nombramiento y cese de director y/o representante legal de la empresa; cambios de clasificación; modificaciones sustanciales de los estatutos sociales; alteraciones de las condiciones que se tuvieron en cuenta para conceder la autorización original; periodos de apertura y cierre del establecimiento; suspensión y cese de la actividad; etc.

De esta forma, los registros se convierten en instrumentos administrativos de control sobre las empresas turísticas, a la vez que actúan de mecanismo de garantía frente a terceros.

\section{RESTRICGIONES IMPUESTAS EN RELACIÓN CON LA FORMA JURÍDICA DE LAS EMPRESAS DEDICADAS A LA INTERMEDIA- CIÓN TURÍSTICA}

La normativa sectorial prohíbe, en determinados casos, el acceso a la titularidad de una actividad empresarial a las personas físicas o bien reduce el tipo de personas jurídicas que puede acceder a ella, con la finalidad de proteger los intereses públicos presentes, así como, los derechos de consumidores y usuarios de sus productos o servicios, procurando alcanzar la máxima seguridad económica en el desarrollo de la empresa y una mayor transparencia en su actividad. El requerimiento de que una actividad empresarial deba ser gestionada preceptivamente por un determinado tipo de persona jurídica (sociedad anónima o limitada, por ejemplo) permite la incorporación de limitacio- 
nes o garantías adicionales, en relación con su forma de constitución, importe del capital social mínimo y su desembolso inicial, exclusividad en el objeto social, control sobre las modificaciones estatutarias, porcentajes de participación en el capital de la empresa, etc., aspectos que serían más difíciles de controlar en otro tipo de entidades ${ }^{48}$. Así ocurre en nuestro ordenamiento, por ejemplo, con las entidades de crédito, establecimientos financieros, entidades aseguradoras, empresas televisivas, sociedades de capital-riesgo, sociedades deportivas, sociedades de servicios de inversión en el mercado de valores, etc.

La imposición de limitaciones de acceso a la titularidad de las agencias de viajes se introdujo en nuestro ordenamiento de forma progresiva. Así, la primera reglamentación de agencias de viajes, aprobada por Decreto de 19 de febrero de 1942, no impuso limitación alguna en este sentido. El ulterior Decreto 735/1962, de 29 de marzo, previó inicialmente, la titularidad tanto de personas físicas como de sociedades mercantiles, con lo cual, excluyó cualquier entidad jurídica no considerada como sociedad mercantil (sociedades civiles), aunque impuso la forma de sociedad mercantil para las agencias clasificadas en el grupo A (Art. 4). Pero, a continuación, la Orden de 28 de febrero de 1963, de desarrollo del Decreto 735/1962, exigió, además, la suscripción de capitales sociales mínimos para todas las agencias de viajes ${ }^{49}$. La restricción se amplió con el reglamento aprobado por Decreto 1524/1973 y desarrollado por Orden de 9 de agosto de 1974, pues ordenó que todas las agencias de viajes se constituyeran como sociedad mercantil, y, finalmente, la Orden de 14 de abril de 1988, de desarrollo del Real Decreto 271/1988, incrementó la limitación a dos únicas formas jurídicas: sociedad anónima o limitada. Así, no sólo se excluyeron de la titularidad de estas empresas a las personas físicas, sino también a las personas jurídicas que no adquieren la forma exigida de sociedad anónima o limitada, quedando descartadas, por tanto, las sociedades colectivas, comanditarias, comanditarias por acciones, cooperativas, etc. La imposición de estas formas jurídicas, fruto del acuerdo adoptado en Conferencia Sectorial, se trasladó a los reglamentos autonómicos de agencias de viajes.

48 Vid. GONZÁLEZ FERNÁNDEZ, B., "Reflexiones sobre la exigencia de forma jurídica específica para las agencias de viajes: la posibilidad de agencias de viajes - personas físicas”, en Derecho y Turismo, I y II Jornadas de Derecho Turístico, Dirección General de Planificación Turística de la Consejería de Turismo de la Junta de Andalucía, Sevilla, 1999, pp. 385-397.

49 A las agencias del grupo A, dos millones de pesetas y a las del grupo B, 400.000 pesetas. 
Sin embargo, esta situación, inicialmente homogénea en todo el Estado, restrictiva respecto a la titularidad de las agencias, ha ido complicándose en los últimos diez años, a raíz de diversas modificaciones legales. Así, por una parte, la Ley 21/1995, de 6 de julio, de Viajes Combinados que, al definir tanto al «organizador», como al «detallista» (Art. 2), se refiere siempre a "la persona física o jurídica", admitiendo, por tanto, ambas formulaciones jurídicas, para remitirse, en su Disposición adicional $2^{\underline{a}}$ a lo que establezca la respectiva normativa administrativa. Posteriormente, entra en juego la ordenación impuesta por las Leyes de Turismo aprobadas por las diferentes Comunidades Autónomas. Así, un grupo de Leyes, modificando la posición de partida, considera de forma expresa la posible titularidad de las agencias de viajes, tanto por personas físicas como, por personas jurídicas, sin límite en cuanto a la tipología de estas últimas. En esta situación se encuentran las Leyes de Turismo de Andalucía, Baleares, Castilla-La Mancha, Comunidad de Valencia y País Vasco ${ }^{50}$. Sin embargo, otro grupo importante de Leyes de Turismo, no aclara de forma expresa la cuestión, al referirse de forma genérica a la «empresa», sin fijar limitación respecto a su configuración jurídica. Así ocurre en las Leyes de Turismo de Castilla y León, Cataluña, Extremadura, Galicia, Comunidad de Madrid, Principado de Asturias, Región de Murcia y La Rioja. Consideramos que, al no imponer la Ley ninguna limitación que afecte a la forma jurídica del titular de la empresa, tampoco debe admitirse la inclusión de restricción alguna por vía reglamentaria, teniendo en cuenta además, como se ha indicado, que la Ley de Viajes Combinados permite la titularidad tanto de personas físicas, como de personas jurídicas. De este segundo grupo, las disposiciones reglamentarias de Castilla y León, Extremadura, Galicia, Comunidad de Madrid y La Rioja, ya han previsto la titularidad tanto de personas físicas comojurídicas. La problemática se mantiene, en cambio, en las Comunidades Autónomas de Cataluña, Principado de Asturias y Región de Murcia. En estos tres supuestos, pese a que la Ley de Turismo no establece ningún límite subjetivo a la titularidad de la agencia de viajes, sus disposiciones reglamentarias de desarrollo sí han impuesto la necesidad de constituirse en sociedad anónima o de responsabilidad limitada, pero, todas ellas fueron promulgadas con anterioridad a la correspondiente Ley de Turismo ${ }^{51}$. Por nuestra parte consi-

${ }^{50}$ En relación con la normativa andaluza, Vid., SÁNCHEZ RUIZ, I., "Las empresas de intermediación turística en la Ley del Turismo de Andalucía", en Derecho y Turismo, III Jornadas de Derecho Turístico, Consejería de Turismo y Deporte. Junta de Andalucía, Sevilla, 2000, pp. 337-338.

${ }^{51}$ Los Reglamentos de Agencias de Viajes del Principado de Asturias (Decreto 31/1988, de 18 de febrero) y Región de Murcia (Decreto 115/1987, de 24 de diciembre) son los originales, aprobados al amparo de la Conferencia Sectorial de Turismo que limitó la titularidad de las agencias de viajes a sociedades anónimas y limitadas. La normativa de Cataluña, en cambio, se aprobó por Decreto 168/1994, de 30 de mayo, en sustitución del original Decreto 45/1988, de 13 de enero, pero ambos han mantenido la limitación relativa a la personalidad jurídica. 
deramos, teniendo en cuenta, en primer lugar, la postura aperturista adoptada por la Ley estatal de Viajes Combinados y, en segundo lugar, la falta de manifestación expresa en sentido contrario de estas Leyes de Turismo, que debe prevalecer el criterio que implique una menor limitación de la libertad de empresa, no debiendo el reglamento establecer distinciones donde no lo ha hecho la Ley a la que desarrolla (ubi lex non distinguit, nec nos distinguere debemus).

En este punto hemos de destacar la declaración formal que incluye la Ley de Turismo de Aragón, al afirmar que "El ejercicio de la actividad turística empresarial es libre, sin más limitaciones que las establecidas en las Leyes, bajo la forma de empresario individual o colectivo de acuerdo con la legislación civil y mercantil" (Art. 25). Al remitirse, pues, a la legislación civil y mercantil de general aplicación, prohíbe que por medio del reglamento se impongan limitaciones a la titularidad de las empresas.

Por último, interesa destacar, en este punto, la posición adoptada por la Ley de Turismo de Canarias, al ser la única Ley que obliga a que las agencias de viajes se constituyan con forma de sociedad anónima o limitada (Art. 48). En este caso, debe prevalecer, pues, el criterio restrictivo al estar amparado por el principio de legalidad.

Podemos resumir, finalmente, nuestra postura en relación con la introducción de límites que afecten al tipo de entidad jurídica que pueda constituirse legalmente en agencia de viajes, en la prevalencia de la reserva de ley en el desarrollo del ejercicio de la libertad de empresa (Art. $53 \mathrm{CE}$, en relación con el art. $38 \mathrm{CE}$ ), de tal forma que sólo por Ley puede imponerse limitación alguna en tal sentido, quedando de esta forma, a salvo, además la previsión que contiene al respecto la Ley de Viajes Combinados, conforme se ha comentado supra.

\section{IMPOSICIÓN DE LIMITACIONES ECONÓMICAS A LA INTER- MEDIACIÓN TURÍSTICA}

La normativa de agencias de viajes impone diversas exigencias económicas con la finalidad de facilitar una mayor protección a los usuarios turísticos, entre las que destacan la fijación de un capital social mínimo y la obligación de que éste se encuentre totalmente desembolsado; la necesidad de suscribir y mantener una fianza y la contratación permanente de una póliza de seguros. Ya el Decreto de 19 de febrero de 1942 introdujo el requisito de la póliza de responsabilidad civil (Art. 3) y de la fianza (Art. 6), con diferentes caracterís- 
ticas en función del tipo de agencia de viajes de que se tratara. La subsiguiente Orden de 26 de febrero de 1963, manteniendo estas prescripciones con algunas variantes, incorporó, por vez primera, la relativa al capital social o inversión mínima destinada al negocio ${ }^{52}$. Las disposiciones posteriores, por su parte, únicamente llevaron a cabo modificaciones relativas a las cuantías y requisitos específicos de estas obligaciones económicas, pero conservando los tres tipos enunciados, capital social, fianza y póliza de seguros. De esta forma, la última reglamentación estatal aprobada por Orden de 14 de abril de 1988 procedió a regular detalladamente estas tres limitaciones económicas. En primer lugar, la póliza de seguros, que se impone para afianzar el normal desarrollo de la actividad de la agencia garantizando la cobertura de los riesgos posibles, siendo la responsabilidad de ésta directa o subsidiaria, según se hayan utilizado o no medios propios en la prestación de los servicios contratados. La póliza de seguros cubre tres bloques de responsabilidad: La responsabilidad civil por explotación del negocio; la responsabilidad civil subsidiaria y la responsabilidad por daños patrimoniales primarios. Por cada bloque de responsabilidad habrá de cubrir una cuantía mínima de 25.000.000 de pesetas. En segundo lugar se contempla la fianza de las agencias de viajes, que sufre una importante modificación respecto a lo previsto en la normativa precedente. Por una parte, se regula la póliza individual por importe de 20.000 .000 de pesetas para las agencias mayoristas, 10.000 .000 de pesetas para las minoristas y 30.000 .000 de pesetas para las mayoristas-minoristas, cantidades cubren hasta seis establecimientos, incrementándose en dos millones de pesetas por cada uno nuevo. Pero, por otra parte, se admite la constitución de fianzas colectivas sumando el 50 por ciento de las fianzas individuales y con un importe global mínimo de 400.000 .000 de pesetas, cubriendo, mediante esta fórmula hasta seis establecimientos por agencia, incrementándose la cantidad en un millón más por cada establecimiento adicional. La fianza queda afecta a resolución judicial declaratoria de responsabilidad económica de la agencia por la prestación de servicios al usuario final o al cumplimiento del laudo dictado por las Comisiones Arbitrales de Agencias de Viajes. Finalmente, en relación con el capital social de la empresa, el reglamento determina su importe mínimo, totalmente desembolsado, de 30.000 .000 de pesetas para las agencias mayoristas-minoristas; 20.000.000 de pesetas para las mayoristas y 10.000.000 de pesetas para las minoristas (Art. 5). Esta imposición de capitales sociales por importe (y en condiciones de desembolso) superior al previsto legalmente por

\footnotetext{
52 La cuantía del capital social requerido era de dos millones para las agencias del grupo A y 400.000 pesetas para las del grupo B. Posteriormente, la Orden de 12 de abril de 1966, impuso a las agencias mayoristas un capital mínimo de cinco millones de pesetas.
} 
la normativa correspondiente al tipo de sociedad de que se trate (anónima o limitada) entraña, como veremos, serios problemas de legalidad.

Inicialmente, la regulación autonómica en la materia recoge estas medidas, si bien, sus ulteriores modificaciones o la aparición de nuevos reglamentos, provoca una alteración significativa, particularmente en lo referente al requisito del capital social de la empresa. En la actualidad, siete reglamentos autonómicos han suprimido el requisito del capital social mínimo superior al impuesto por la legislación mercantil con carácter general: Andalucía, Aragón, Castilla y León, Extremadura, Comunidad de Madrid ${ }^{53}$, La Rioja y Comunidad de Valencia. En las restantes Comunidades Autónomas se mantiene el importe del capital social mínimo y totalmente desembolsado que impuso la normativa estatal de $1988^{54}$. En estas disposiciones, se impone adicionalmente la obligación de notificar a la Administración las alteraciones del capital social y se regula como cláusula de revocación del título-licencia, la reducción del capital por debajo del mínimo establecido. Respecto a la póliza de responsabilidad civil y a la fianza o garantía, se incorporan como requisitos obligatorios en todos los reglamentos autonómicos, con escasas variaciones en su regulación.

Estas obligaciones impuestas por el ordenamiento a las agencias de viajes tienen carácter imperativo, permanente, con una repercusión económica directa en la empresa e implican un tratamiento diferenciado frente a la actividad empresarial común, entendiendo como tal, aquélla carente de regulación especial, es decir, dirigida de forma expresa y exclusiva a determinado sector

\footnotetext{
${ }^{53}$ Precisamente el Decreto 99/1996, de 27 de junio por el que se aprueba el RAV de la Comunidad de Madrid se dictó en sustitución del anterior, entre otros motivos, por las Sentencias del Tribunal Superior de Justicia que sancionaban al anterior Reglamento por imponer capitales sociales superiores a los previstos con carácter general en la legislación mercantil aplicable. Por ello, el nuevo Reglamento en su art. 4 in fine, establece entre los requisitos para obtener el títulolicencia que: "Deberá igualmente constar el capital social mínimo exigido en la legislación vigente aplicable a la forma jurídica de la sociedad que se haya constituido".

${ }^{54}$ En esta situación se encuentran los Reglamentos de Agencias de Viajes de Baleares, Canarias, Cantabria, Castilla La Mancha, Cataluña, Galicia, Comunidad de Navarra, Principado de Asturias y Región de Murcia. Únicamente en Baleares y Galicia, al permitir que una persona física sea titular de la agencia, determinan que el capital social mínimo sólo se exigirá a las sociedades mercantiles, aunque la norma balear añade, para las personas físicas que "deberán presentar el justificante acreditativo de estar inscritos en el Registro Mercantil como empresarios individuales con un capital o patrimonio afecto a la actividad que cubra el capital mínimo expresado para cada grupo en el apartado anterior".
} 
empresarial (tales como, entidades financieras, compañías de seguros, empresas de hidrocarburos, etc.). La imposición de este tipo de exigencias económicas a las agencias de viajes plantea dos cuestiones relevantes, por una parte, analizar si las Comunidades Autónomas tienen competencia para su aprobación o, por el contrario, nos encontramos frente a competencias estatales y, por otra, determinar si es suficiente para su imposición una disposición de carácter reglamentario, o se encuentra afectada por reserva de ley.

Para contestar a la primera cuestión planteada debemos considerar las competencias que las Comunidades Autónomas, por un lado, y el Estado, por otro, pueden esgrimir como propias. En efecto, según se ha visto en el apartado correspondiente, las Comunidades Autónomas gozan de la potestad de ordenación del turismo en su ámbito territorial, facultad que aunque pueda parecer en cierta medida indeterminada, para algunos autores ${ }^{55}$, abarca, en todo caso, la posibilidad de imponer y hacer uso de distintos instrumentos de intervención sobre el turismo, que se establecerán por vía normativa: autorizaciones y licencias; clasificación de establecimientos o empresas; inscripción registral; facultad de inspección y control; potestad sancionadora; imposición de obligaciones y prohibiciones; etc. ${ }^{56}$ Es evidente que la competencia exclusiva que ostentan las Comunidades Autónomas de ordenación sobre un determinado sector económico, en nuestro caso el turismo, comprende la posibilidad de dictar disposiciones de carácter general, tanto normas con rango de Ley, aprobadas por sus respectivos Parlamentos, como disposiciones reglamentarias de desarrollo ${ }^{57}$.

\footnotetext{
${ }^{55}$ Así lo entiende BLANQUER CRIADO, D., que parte de su consideración como concepto jurídico indeterminado, en "¿Ordenación o desordenación del turismo?, en Documentación Administrativa, núm. 259-260, 2001, p. 292.

${ }^{56}$ Así, Joaquín Arozamena Sierra mantiene en su voto particular a la STC 125/1984 que "Está claro para mí que la competencia en materia de ordenación del turismo pertenece en exclusividad a las Comunidades Autónomas y que dentro de esta ordenación se comprenden las técnicas de intervención, en su variedad, de autorizaciones, sanciones, vigilancia, etc., y, desde luego, en lo que se refiere al subsector hotelero, el régimen de clasificación de los establecimientos".

${ }^{57}$ En este sentido interpreta la doctrina la potestad de «ordenación del turismo» que la Constitución faculta a las Comunidades Autónomas a asumir como competencia exclusiva. Así, FERNÁNDEZ-OBANZA CARRO, J., afirma que "es una competencia exclusiva en el sentido propio de la palabra, es decir, en el sentido de atribuir a las Comunidades Autónomas todas las competencias y funciones ejercitables en esta materia, tanto normativas como ejecutivas (...)", en "Competencias y organización de las Administraciones Turísticas", en Actualidad Administrativa, núm. 21, 1999, p. 634. Igualmente, MIR BAGÓ, J., en referencia a la competencia de ordenación del tu-
} 
Esta potestad de «ordenación del turismo» se ha puesto de manifiesto, con especial intensidad, al dictarse las distintas Leyes autonómicas de «ordenación del turismo» $\mathrm{o}$, simplemente, Leyes de Turismo ${ }^{58}$. Ahora bien, esta competencia legislativa y reglamentaria que las Comunidades Autónomas pueden desplegar con objeto de «ordenar» el turismo en su territorio ha de ejercerse respetando las competencias generales que tiene reservadas el Estado y que presentan una especial incidencia en el turismo. Así, las Comunidades Autónomas no pueden legislar sobre las "condiciones de obtención, expedición y homologación de títulos académicos y profesionales" dentro del campo del turismo (Art. 149,30ํㅡㄹ); sobre la propiedad industrial respecto a marcas o rótulos comerciales de las em-

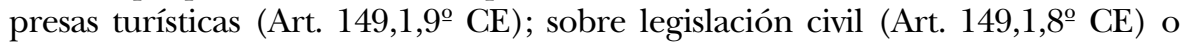
mercantil (Art. 149,1, ${ }^{\circ} \mathrm{CE}$ ) referidas a la actuación de las empresas turísticas; sobre las relaciones internacionales en el campo del turismo (Art. 149,1,3 $\mathrm{CE}$ ); sobre comercio exterior (Art. 149,1,10트), entre otras, según se analizó supra.

Precisamente es la competencia estatal sobre «legislación mercantil» (Art. $149,1,6^{\circ} \mathrm{CE}$ ) la que algunos autores enfrentan a la actuación legislativa y reglamentaria de las Comunidades Autónomas sobre las obligaciones económicas impuestas a las agencias de viajes ${ }^{59}$. Efectivamente, debemos considerar

rismo que corresponde a la Comunidad Autónoma de Cataluña, afirma que su ejercicio "es mensurable jurídicamente mediante sus actos y Reglamentos y demás normas; ante la práctica imposibilidad de hacer un seguimiento representativo de los primeros, nos limitamos a considerar la producción normativa, que afecta a los siguientes campos (...)", en "Turismo", en Comentarios sobre el Estatuto de Autonomía de Cataluña, Vol. I, Instituto de Estudios Autonómicos, Barcelona, 1990, p. 628.

${ }^{58}$ Las Comunidades Autónomas al aprobar Leyes generales reguladoras de la actividad turística han preferido, de forma mayoritaria, la utilización de la denominación "Ley de Turismo", aunque en Canarias, Comunidad de Madrid y País Vasco se han decantado por la expresión específica de "ordenación del turismo" para nominar a dichas Leyes.

${ }^{59}$ Así BLANQUER CRIADO, D., afirma que "podría argumentarse que si no se reconoce a las Comunidades Autónomas la posibilidad de dictar esa especie de «reglamentación mercantil especial» entonces se vacían sus poderes de intervención en sectores cuya competencia les corresponde (como es el caso de la ordenación del turismo). Pero en ese caso se abriría un portillo sin pestillo de cierre que en gran medida vaciaría la competencia estatal en materia de legislación mercantil”. Vid. “¿Ordenación o desordenación del turismo?”, op. cit., pp. 301-302. En el mismo sentido se manifiestan SUAY RINCÓN, J. y RODRÍGUEZ GONZÁLEZ, M. P., considerándolo una "manifestación más de una práctica que progresivamente han incorporado las Comunidades Autónomas, cual es la invasión de las competencias constitucionales en materia de legislación mercantil reservada al Estado por el artículo 149,1,6ํㅜ de la CE, dentro de cuyo rótulo se subsume la regulación del estatuto de las empresas y, por ende, el establecimiento de ciertos extremos como son, desde luego, su capital social o el régimen de gestión o administración colegial o unipersonal", en "Régimen jurídico-administrativo de las agencias de viajes (...)", op. cit., p. 460. 
que en los tres supuestos mencionados la normativa autonómica (Ley o Reglamento) se refiere a figuras propias del Derecho mercantil como son la fijación de un capital social mínimo, las pólizas de seguros y las fianzas. Pero, del mismo modo que debemos considerar que la competencia autonómica de ordenación del turismo se encuentra limitada, entre otras, por la competencia estatal sobre la legislación mercantil, también debemos acotar la extensión del término «legislación mercantil». En otras palabras, la competencia sobre legislación mercantil no debe impedir el ejercicio de la capacidad de ordenación sobre un determinado sector de actividad que la Constitución atribuye a la Comunidad Autónoma, e igualmente tampoco debe permitirse que la Comunidad Autónoma ordene el funcionamiento jurídico-mercantil de las empresas. A nuestro juicio, la expresión «legislación mercantil» debe alcanzar a la completa regulación legal de las relaciones jurídico-privadas que se suscitan dentro del funcionamiento de una empresa y en sus relaciones con los clientes y proveedores, en las que se protegen los legítimos intereses, de carácter privado, de las partes intervinientes ${ }^{60}$. En cambio, si la norma autonómica impone un capital social mínimo o un tipo de póliza de seguro o una fianza, no procede a regular dichos institutos jurídicos, puesto que, con relación a su concreta regulación jurídica resulta implícita su remisión a la normativa mercantil correspondiente, cuya aprobación corresponde al Estado. En los dos últimos casos la cuestión parece muy clara y no ha planteado problemas doctrinales relevantes: una norma administrativa puede exigir la contratación de una póliza de seguros o la constitución de fianzas o garantías para asegurar y proteger a los usuarios o clientes de las entidades privadas que resultan admi-

${ }^{60}$ Afirma el Tribunal Constitucional en STC 37/1997, de 27 de febrero, F.J. 2º, que "En efecto, desde la Sentencia citada el Tribunal ha delimitado el alcance de la legislación contractual, civil y mercantil, en relación con otras materias competenciales como el comercio interior, la defensa de consumidores y usuarios, 88/1986 y 61/1991, los Centros de Contratación de Mercancías, la ordenación de los seguros y las cooperativas. El punto de partida argumental de todas las resoluciones ha sido siempre el de la distinción cuidadosa entre, de un lado, lo que es regulación de las relaciones inter privatos y, de otro lado, la regulación de la intervención de los poderes públicos en estas relaciones contractuales -mediante, por ejemplo, actividades de policía administrativa o de establecimiento de servicios de vigilancia, inspección o régimen disciplinario, fundamento jurídico $\left.4 .{ }^{\circ}\right)-$. El primer tipo de regulaciones se ha encuadrado en la materia de legislación civil o mercantil -afirmando que «sólo las reglas de Derecho Privado quedarán comprendidas en la reserva al Estado de la legislación mercantil» e incluyendo en ellas el establecimiento de las condiciones generales de contratación, las modalidades de contratos, la delimitación de su contenido típico, de los derechos y obligaciones en el marco de relaciones contractuales privadas, la forma en la que nacen y se extinguen los derechos y las obligaciones de los empresarios o las condiciones de validez de los contratos privados, en tanto que las actividades públicas del segundo grupo se han incluido en las materias de comercio, defensa de los consumidores, seguros o cooperativas". 
nistrativamente obligadas, utilizando dichas figuras como instrumento de intervención, pero sin determinar cuál deba ser su ordenación jurídica, aunque lógicamente la norma deba señalar las características que una y otra deban ofrecer para que se consideren medios suficientes para el otorgamiento del título-licencia de agencias de viajes. La regulación jurídica de ambas figuras corresponde, pues, al ámbito del Derecho mercantil y, por tanto, se encuentra dentro de la competencia estatal sobre la «legislación mercantil».

En similar situación se encuentran, a nuestro juicio, los supuestos en que la normativa autonómica exige la disposición de un capital social mínimo totalmente desembolsado a la entidad titular de una agencia de viajes. Entendemos que tampoco en este supuesto se produce una auténtica injerencia en la competencia estatal sobre la «legislación mercantil» sino la mera utilización de un instrumento jurídico-mercantil, cual es la determinación del capital social mínimo de una determinada persona jurídica al objeto de ofrecer, de este modo, una mayor garantía económica y de transparencia a los usuarios turísticos y una adecuada protección del turismo, como sector económico cuyo desarrollo y fomento el ordenamiento considera de interés público. La diferencia, en estos casos, entre Derecho público y Derecho privado resulta compleja, como ha manifestado el Tribunal Constitucional, por ejemplo, con ocasión del recurso planteado contra la Ley del Parlamento Vasco 3/1981, de 12 de febrero, sobre Centros de Contratación de Cargas en el transporte terrestre de mercancías, afirmando que ${ }^{61}$ : "Como es obvio, toda la actividad económica y, dentro de ella, la actividad que, en el sentido más amplio, podemos designar como actividad mercantil, aparece disciplinada hoy en las sociedades que siguen el modelo de la economía de mercado, por un conjunto de normas en donde se mezclan de manera inextricable el Derecho público y el Derecho privado, dentro del cual hay que situar sin duda el Derecho mercantil. En efecto, aquellas concepciones del mismo que lo definen como «la parte del derecho patrimonial privado que regula el estatuto profesional de los titulares de las instituciones de producción económica características del sistema capitalista, los empresarios mercantiles, así como el tráfico que éstos realizan para colocar en el mercado los bienes y servicios producidos», o, más sucintamente, «el derecho privado de la actividad económica desarrollada por los empresarios», que cuentan sin duda entre los más autorizados de nuestra doctrina, trasladan en último término el problema de la delimitación conceptual del Derecho mercantil, al menos en la dimensión que ahora nos importa, al de la delimitación entre Derecho privado y Derecho público".

\footnotetext{
${ }^{61}$ F.J. $2^{\circ}$ STC $37 / 1981$, de 16 de noviembre.
} 
En cambio, sí creemos que pertenece al campo de la «legislación mercantil», y por tanto es una competencia estatal vulnerada por algunas disposiciones autonómicas, la regulación jurídica de los contratos mercantiles dentro del campo del turismo, ya se refieran al ámbito de la intermediación turística, como los contratos de viajes combinados, servicios sueltos y demás servicios prestados por las agencias de viajes, según se ha visto anteriormente, ya a otros campos dentro del turismo, como el contrato de hospedaje, contrato de transporte de viajeros, etc. Cuestión ésta también aclarada por el Tribunal Constitucional en la citada Sentencia 37/1981, de 16 de noviembre: "No es necesario, para dar solución a la controversia aquí planteada, entrar en ulteriores precisiones acerca de cuál sea el criterio adecuado para trazar los límites entre la legislación mercantil y la legislación correspondiente a otras ramas del Derecho, pues es claro que sea cual fuere el criterio que se adoptase, aquélla habrá de incluir en todo caso la regulación de las relaciones jurídico-privadas de los empresarios mercantiles o comerciantes en cuanto tales. Sólo a través de sus órganos centrales puede el Estado determinar cuál es el ámbito propio de la actividad libre del empresario mercantil y sólo la legislación emanada de esos órganos centrales puede regular la forma en que nacen y se extinguen los derechos y obligaciones a que el ejercicio de esa actividad puede dar lugar y el contenido necesario de aquéllos y éstas".

En contra del parecer manifestado por el Tribunal Constitucional comprobamos que las disposiciones reglamentarias de agencias de viajes dictadas por las Comunidades Autónomas contienen, junto a aspectos puramente jurídico-administrativos que reflejan el ejercicio de potestades administrativas, dictados en aplicación de su competencia de ordenación turística, tales como requisitos de autorización, documentación a presentar y procedimiento; exigibilidad y otorgamiento del título-licencia; inscripción registral; actuaciones contra el intrusismo profesional; sanciones; medidas de fomento; etc., otros aspectos puramente mercantiles integrados bajo el epígrafe de «el ejercicio de actividades de agencias de viajes», que con mayor o menor extensión incluyen todos los Reglamentos autonómicos ${ }^{62}$, tratando aspectos tales como la identificación comercial de las agencias; los criterios para realizar publicidad de los servicios; tipos de contratos; información a facilitar a los usuarios sobre los ser-

\footnotetext{
${ }^{62}$ Sobre esta cuestión el RAV Andalucía ha incluido, de forma muy acertada, en su Exposición de Motivos y en referencia a la vigencia de la normativa estatal de carácter jurídico-privado, la siguiente reflexión: "No obstante, las previsiones de carácter jurídico-privado contenidas en la normativa estatal seguirán siendo de aplicación, toda vez que al determinar el contenido básico de los tipos contractuales, forman parte de la competencia exclusiva del Estado sobre la legislación civil y mercantil”.
} 
vicios a contratar; régimen de precios; regulación del depósito y la anulación de reserva; entrega de documentación al usuario; cumplimiento del contrato; etc. Se trata, en definitiva, de materias jurídico-privadas relativas al funcionamiento de las agencias, incidiendo en ámbitos que la Constitución reserva al Estado al formar parte de su competencia exclusiva sobre «legislación mercantil». A nuestro juicio, el contenido enunciado de estas disposiciones supone una trasgresión de la distribución de competencias entre el Estado y las Comunidades Autónomas, conforme determina la Constitución.

La segunda cuestión que debemos analizar se refiere al rango jerárquico del instrumento normativo que haya de utilizarse para la imposición de las obligaciones económicas estudiadas. Es importante determinar en este punto el papel que puede desempeñar el reglamento, por tratarse del mecanismo utilizado habitualmente, tanto por el Estado como por las Comunidades $\mathrm{Au}$ tónomas para llevar a cabo la «ordenación» de la actividad empresarial de intermediación turística. Entendemos que, particularmente la obligación por la que se impone la existencia de un capital social mínimo y, además, totalmente desembolsado son aspectos cruciales que deben quedar reservados a disposiciones con rango de Ley, por afectar de forma directa al ejercicio de la libertad de empresa sometida a reserva de Ley, conforme establece el art. 53 CE, y por implicar, además, una modificación del régimen general de las sociedades anónimas y de responsabilidad limitada, contenido en normas con rango de Ley. Efectivamente, el régimen jurídico de las sociedades anónimas y de las sociedades de responsabilidad limitada se contiene en normas con rango de Ley que imponen respecto al capital social un régimen común, consistente, para las sociedades anónimas en un capital social mínimo de 10.000.000 de pesetas, totalmente suscrito, pero desembolsado como mínimo sólo en su cuarta parte y para las sociedades de responsabilidad limitada un capital social mínimo de 500.000 pesetas, totalmente desembolsadas desde su fundación ${ }^{63}$.

Entendemos, por tanto, que sería necesario que, la imposición de un capital social mínimo, superior al exigido por la regulación general enunciada, así como, la obligación de su completo desembolso inicial, se establecieran en

${ }^{63}$ Vid. arts. 4 y 12 de la Ley de Sociedades Anónimas y art. 4 de la Ley de Sociedades de Responsabilidad Limitada, respectivamente. En relación con los límites impuestos al capital social por la normativa mercantil frente a la normativa turística, sólo en las agencias de viajes minoristas constituidas en forma de sociedad anónima, coinciden las cuantías establecidas por una y otra (10.000.000 ptas), no así el mínimo de capital desembolsado. 
una norma con rango legal, habilitando al reglamento para desarrollar dicha previsión. En este sentido se ha manifestado el Tribunal Supremo, en su Sentencia de 29 de abril de 1997, resolviendo el recurso interpuesto contra el reglamento de agencias de viajes de la Comunidad de Madrid, afirmando que: "No parece conforme al ordenamiento jurídico en cuanto supere el mínimo exigible por la normativa propia de tales sociedades, ya que a través de una norma de carácter reglamentario, sin cobertura legal habilitante, no puede modificarse lo dispuesto en una norma jerárquicamente superior. El capital social mínimo para las sociedades anónimas y de responsabilidad limitada está establecido respectivamente en 10.000.000 de pesetas (Real Decreto Legislativo 1564/1989, de 22 de diciembre) y 500.000 pesetas (Ley 2/1995, de 23 de marzo), por lo que la exigencia establecida en el artículo 5,a), párrafo último, que sin distinguir entre las formas societarias anónimas o limitada exige unos mínimos superiores a los establecidos en normas de rango superior, debe ser anulada (...)". A nuestro juicio, este papel debe ser desempeñado, en razón a su especialidad, por las Leyes de Turismo, particularmente en cuanto se refiere a la exigibilidad de un capital social mínimo y su completo desembolso. Esta función, sin embargo, sólo es efectuada con nitidez por la Ley de Turismo de las Islas Baleares (Art. 31,1 in fine): "Igualmente deberá constar un capital mínimo de: 30.000 .000 de pesetas para el grupo de mayoristas-detallistas; 20.000 .000 de pesetas para le grupo de mayoristas; 10.000 .000 de pesetas para el grupo de detallistas". Las restantes Leyes o se refieren de forma genérica a la exigencia de un capital mínimo ${ }^{64}$, para cuya concreción se remiten a las disposiciones reglamentarias de desarrollo, o eluden referirse a esta cuestión. En algunos casos, en cambio, las referencias al capital social quedan relegadas a la regulación de la disciplina turística al tipificar como infracción el incumplimiento de las previsiones en relación al capital social mínimo, sin que la cuantía y características de éste se hayan especificado en la propia Ley. Por nuestra parte consideramos necesario, en aplicación de los principios de legalidad y jerarquía normativa, que la Ley de Turismo imponga, en caso de considerarlo preciso, las condiciones específicas en relación con el capital social, sin que, en caso contrario, éstas pueden imponerse por vía reglamentaria. Por tanto, conforme a nuestro razonamiento, los Reglamentos de Agencias de Viajes de Canarias, Cantabria, Castilla-La Mancha, Cataluña, Galicia, Navarra, Principado de Asturias y Región de Murcia se exceden en su capacidad para imponer capitales sociales superiores a los exigidos en la precitada legislación mercantil, siendo válidas, en cambio, las previsiones incluidas por el Reglamento de Agencias de Viajes de Baleares, al ampararse en lo previsto en su respectiva Ley de Turismo.

\footnotetext{
${ }^{64}$ Así ocurre en las Leyes de Turismo de Canarias, Galicia y País Vasco.
} 


\section{LA CONCESIÓN DE LA EXCLUSIVIDAD PARA EL EJERCICIO DE DETERMINADAS ACTIVIDADES DE MEDIACIOON TURÍS- TICA}

Otra característica que presenta la ordenación de las empresas de intermediación turística es la cláusula de exclusividad en la prestación de determinados servicios. Por medio de este instrumento el ordenamiento pretende alcanzar una mayor profesionalización en la prestación de dichos servicios, a la vez que cobran sentido las garantías y condicionantes económicos que, como hemos visto, se imponen a estas empresas en beneficio de los usuarios turísti$\cos ^{65}$. Se concita en este caso, además, la circunstancia de que las actividades que normativamente quedan reservadas a las agencias de viajes (y, en su caso, a las centrales de reservas) resultan las más relevantes dentro de las que se corresponden con la organización y mediación de servicios turísticos, como veremos a continuación.

Ya la primera normativa de agencias de viajes, asignó a éstas en exclusividad, la venta de billetes y reserva de plazas para toda clase de transportes regulares; la reserva de habitación y servicios en hoteles; la organización de viajes combinados; y, finalmente, la organización de viajes y excursiones colectivas y visitas de ciudades. El Decreto fortalece esta reserva indicando que dichas actividades "califican la actividad mercantil de una agencia de viajes", considerando ilegal y sancionable en vía administrativa su realización por otras empresas o entidades, sin la correspondiente autorización.

El Decreto 735/1962, de 29 de marzo, confirmó las actividades de intermediación que se declaraban exclusivas de las agencias de viajes, a través de una redacción más elaborada e incluyendo la representación de agencias extranjeras. Así, se otorga la exclusividad a las agencias de viajes respecto a la mediación en la venta de billetes y reserva de plazas en toda clase de medios de transporte; las reservas de habitaciones y servicios en establecimientos hoteleros; la organización de viajes turísticos comprendiendo todos los servicios propios de los viajes «a forfait»; y, por último, la representación de otras agencias, nacionales o extranjeras, para la prestación, en su nombre, de cualquiera de los servicios enumerados. La Orden de 26 de febrero de 1963, de desarrollo

${ }^{65}$ La protección que otorga a los derechos del usuario turístico se sustenta en lo establecido en el art. 51 CE: "Los poderes públicos garantizarán la defensa de los consumidores y usuarios, protegiendo, mediante procedimientos eficaces, la seguridad, la salud y los legítimos intereses económicos de los mismos". 
del Decreto 735/1962, detalla y amplía las actividades que se reservan en exclusiva a las agencias, así, en relación con los medios de transporte incorpora la reserva directa de plazas, y el depósito, expedición y transferencia de equipaje en relación con los viajes que reserve; la reserva de habitaciones se extiende a establecimientos similares a los establecimientos hoteleros; en los viajes se incluye, además de la organización, la realización, ampliada a excursiones, visitas a poblaciones y circuitos turísticos; incrementa su actuación en el turismo receptivo, mediante la asistencia a los turistas en sus viajes o estancias en España, incluyendo los servicios de intérpretes y acompañantes turísticos (guías); y, finalmente engloba la actividad propia de las agencias mayoristas: elaborar proyectos y organizar viajes y servicios turísticos complejos para su comercialización a través de agencias de prestación directa al público ${ }^{66}$.

La siguiente normativa de agencias de viajes, aprobada por Decreto 1524/1973, de 7 de junio y desarrollada por la Orden Ministerial de 9 de agosto de 1974, mantiene básicamente los elementos que configuran la reserva de exclusividad a favor de las agencias de viaje legalmente constituidas, aunque con interesantes correcciones. La relación de «actividades propias» que gozan del privilegio de exclusividad sufre modificaciones dirigidas fundamentalmente a aclarar su contenido y, especialmente, a mejorar su redacción técnica, que queda detallada en los siguientes términos: la mediación en la venta de billetes y reserva de plazas en toda clase de medios de transportes; la reserva de habitaciones y servicios en los establecimientos hoteleros y demás alojamientos turísticos; la organización, venta y realización de servicios combinados y viajes «a forfait», incluyendo la recepción, asistencia y traslado de los clientes; y la actuación, por delegación y corresponsalía de otras agencias nacionales o extranjeras, para la prestación en su nombre, y a la clientela de éstas, de cualquiera de los servicios reservados. Las modificaciones que inserta esta normativa se concreta, en primer lugar, en que el depósito, expedición y transferencia de equipajes relacionados con los títulos de transporte que comercialicen las agencias pierde su consideración de actividad exclusiva; en segundo lugar, se da nueva redacción a la actividad de organización, venta y realización de viajes, imprimiéndole una redacción técnica más adecuada y limitando el ámbito reservado a los servicios combinados y viajes «a forfait», e

\footnotetext{
${ }^{66}$ Como se ha indicado anteriormente, esta actividad que desarrollan las agencias mayoristas se regularán por medio de una normativa específica aprobada por Orden Ministerial de 12 de abril de 1966.
} 
incluyendo la recepción, asistencia y traslado de los clientes ${ }^{67}$; y, finalmente, se suprime la referencia explícita a las actividades de las agencias mayoristas que debemos considerar incluidas dentro de la actividad propia de "organización, venta y realización" de viajes.

La técnica de reservar en exclusividad las actividades centrales de la intermediación turística se incorpora finalmente a la última reglamentación estatal en la materia, constituida por el Real Decreto 271/1988, de 25 de marzo, y por la Orden Ministerial de desarrollo de 14 de abril de 1988, considerando como tal, la mediación en la venta de billetes o reserva de plazas en toda clase de medios de transporte, así como en la reserva de habitaciones y servicios en las empresas turísticas y particularmente en los establecimientos hoteleros y demás alojamientos turísticos; la organización y venta de los denominados paquetes turísticos ${ }^{68}$; y la actuación como representante de otras agencias nacionales o extranjeras para la prestación en su nombre y a la clientela de éstas de cualquiera de los servicios propios de las agencias de viajes.

La reserva de exclusividad a favor de las agencias de viajes se incluye en los reglamentos autonómicos y, posteriormente en las Leyes de Turismo. Consideramos, empero, a la luz del texto constitucional y de los sucesivos pronunciamientos del Tribunal Constitucional relativos a la protección de la libertad de empresa, que ha de ser una norma con rango de Ley la que efectúe una reserva de ámbitos materiales de actuación para un tipo específico de empresa, en detrimento de las restantes, por implicar una restricción significativa al libre ejercicio de las actividades empresariales turísticas. $\mathrm{Si}$, como hemos visto, en su origen y evolución la reserva de exclusividad se ha impuesto por medio de las disposiciones reglamentarias reguladoras de las actividades de las agencias de viajes, con la promulgación de las Leyes de Turismo por parte de las Comunidades Autónomas, en ejercicio de su competencia de «ordenación del turismo» han de ser éstas las que asuman dicha función, salvo en lo que se refiera a la organización y realización de viajes combinados, materia sobre la que

${ }^{67}$ Determinadas actividades reservadas anteriormente a las agencias de viajes respecto a visitas a poblaciones y asistencia a los turistas, así como los servicios de intérpretes o acompañamiento pasan a ser ejercidas por los guías, guías-intérpretes y correos de turismo, conforme a la regulación de su actividad efectuada por Orden Ministerial de 31 de enero de 1964.

${ }^{68}$ La Orden considera como paquete turístico el conjunto de servicios turísticos, tales como manutención, transporte, alojamientos, etc., ofertado por la agencia o proyectado por ésta a solicitud del cliente, a un precio global preestablecido. 
el Estado conserva competencia legislativa plena, ejercida con la promulgación de la Ley de Viajes Combinados.

Podemos considerar, pues, la reserva de exclusividad como una prerrogativa que el ordenamiento otorga a las agencias de viajes, que implica que únicamente estas empresas puedan prestar las actividades fundamentales que comprende la intermediación turística. Su finalidad, como se ha indicado, es fortalecer la profesionalización en la prestación de servicios turísticos, así como la máxima protección a los usuarios turísticos. Supone, por tanto, una restricción significativa para las restantes empresas turísticas, dejando a salvo las excepciones previstas por el propio ordenamiento $^{69}$, particularmente respecto a otras empresas de mediación, que en ningún caso podrán llevar a cabo dichas actividades, aunque sí otras de intermediación, por ejemplo, las que tengan la consideración de «actividades complementarias» de las agencias de viajes, salvo que también para estas empresas (distintas de las agencias de viajes) se limite su campo de actuación, como ocurre, por ejemplo con las centrales de reservas ${ }^{70}$. En esta situación se encuentran los organizadores profesionales de congresos, que se dedican a actividades de mediación para la organización y realización técnica de congresos y eventos, pero que no pueden realizar las funciones propias de las agencias de viajes, debiendo contratar con éstas, por ejemplo, la reserva de alojamientos turísticos o la emisión de billetes en los diferentes medios de transportes que vayan a utilizar los congresistas, salvo que en el OPC recaiga igualmente la condición legal de agencia de viajes, en cuyo caso podrá realizar todas las actividades mencionadas ${ }^{71}$.

${ }^{69}$ Se excluye de la reserva de exclusividad a favor de las agencias de viajes la facultad que tienen las empresas que prestan servicios turísticos, fundamentalmente los establecimientos de alojamiento turístico y las empresas de transporte de viajeros, para reservar y contratar directamente sus servicios con los clientes, sin la intervención de una agencia de viajes.

${ }^{70}$ Así, el art. 47 de la LT Aragón y el art. 52 LT Principado de Asturias, determinan que las centrales de reserva son "las empresas turísticas que se dedican exclusivamente a reservar servicios turísticos". Por su parte, la LT Andalucía le otorga mayor campo de actuación, siempre y cuando no perciban la contraprestación económica del usuario, al considerar que son centrales de reserva "quienes se dedican a la intermediación en la prestación de cualesquier servicios turísticos, sin que, en ningún caso, puedan percibir de los usuarios turísticos contraprestación económica por su intermediación” (Art. 47,4). Finalmente, la LT La Rioja, al regular las centrales de reserva utiliza un criterio mixto, excluyéndolas de ciertas actividades propias de las agencias de viajes: "se dedican principalmente a reservar servicios turísticos de forma individualizada. Las centrales de reserva no tendrán la capacidad para organizar viajes combinados, ni excursiones de un día y, en ningún caso, podrán percibir de los usuarios turísticos contraprestación económica por su intermediación” (Art. 18,2).

71 Vid., al respecto, Disposición Adicional primera del Decreto 301/2002, de 17 de diciembre, de agencias de viajes y centrales de reservas de Andalucía. 
Por otra parte, el ordenamiento exige a las agencias de viajes la exclusividad en su actuación mercantil de intermediación turística, es decir, limita el campo de acción de las agencias de viajes, que no pueden dedicarse a actividades diferentes a las que en tal sentido les fije el ordenamiento. El ámbito material de esta limitación es empero diferente cuantitativa y cualitativamente a la denominada «reserva de exclusividad». Ésta última, como hemos visto, alcanza únicamente a las actividades de mediación más significativas, tales como, venta de billetes y reserva de plazas en medios de transportes y reserva de habitaciones y servicios en empresas de alojamiento turístico; organización y venta de viajes combinados; y la actuación como representante de otra agencia nacional o extranjera para la prestación de alguno de los servicios anteriormente mencionados. Sin embargo, la actividad de la agencia encuentra sus límites en ámbitos fronterizos más amplios, al incluir las denominadas «actividades complementarias» de mediación u organización de servicios turísticos, en los que no mantiene la exclusiva, tales como, información turística; difusión y venta de material de propaganda; cambio de divisas; venta y cambio de cheques de viaje; expedición y transferencia de equipajes en cualquier medio de transporte; formalización de pólizas de seguros turísticos; alquiler de vehículos; reserva, adquisición y venta de entradas para actividades, espectáculos, monumentos, museos y similares; alquiler de equipamiento para la práctica de turismo deportivo; fletación de medios de transportes; organización de congresos, ferias, convenciones y reuniones; etc ${ }^{72}$. Por tanto, en garantía de una mayor profesionalización en la prestación de los servicios turísticos, el ordenamiento exige a las agencias de viajes exclusividad en su actividad, abarcando ésta, tanto las denominadas «actividades propias», sobre las que las agencias detentan, a su vez, el beneficio de reserva de exclusividad, y las «actividades complementarias».

Centrándonos finalmente en el tratamiento legal de la reserva de exclusividad a favor de las agencias de viajes, debe ponerse de manifiesto, un principio de aplicación general, incorporado en la Disposición Adicional segunda de la Ley 21/1995, de 6 de julio, de Viajes Combinados: "A los efectos de lo previsto en la presente Ley, el organizador y el detallista deberán tener la consideración de agencia de viajes de acuerdo con la normativa administrativa que se dicte al efecto". Puesto que la Ley establece que el organizador es quien or-

${ }^{72}$ En algunas Leyes de Turismo y reglamentos de agencias de viajes se incluye una cláusula abierta que permite la ulterior ampliación de las actividades complementarias a desarrollar por las agencias de viajes, siempre que se refiera a la organización y mediación de servicios turísticos. Vid., a modo de ejemplo, art. 55,1 LT Cataluña y art. 59,2 LT Galicia. 
ganiza de forma no ocasional viajes combinados y los ofrece para su venta o los vende directamente o por medio del detallista y éste es la persona física o jurídica que vende $u$ ofrece en venta el viaje combinado propuesto por el organizador (Art. 2), debemos concluir que la organización y comercialización de los viajes combinados es una actividad empresarial reservada en exclusiva a las agencias de viajes, en todo el Estado español ${ }^{73}$, por aplicación de una ley estatal que, a su vez, es la trasposición al ordenamiento español de la Directiva del Consejo de las Comunidades Europeas de 13 de junio de 1990, relativa a viajes combinados, las vacaciones combinadas y de los circuitos combinados.

Por su parte, las Leyes de Turismo no regulan la reserva de exclusividad a favor de las agencias de viajes de una manera uniforme, y, en ocasiones, dicha reserva queda reducida a la contemplada por la Ley de Viajes Combinados o queda desdibujada en su tratamiento legal o simplemente no existe. Así, las Leyes de Turismo de Galicia y Cataluña son las que proceden a enumerar de forma precisa las actividades propias de las agencias de viajes, afirmando su consideración de actividades exclusivas ${ }^{74}$. Otras Leyes se limitan a reservar ámbitos materiales de actuación, más o menos definidos, como "la mediación y organización de servicios turísticos" en los casos de Castilla y León, Castilla-La Mancha, Comunidad de Madrid, Región de Murcia y País Vasco ${ }^{75}$; la LT La

${ }^{73}$ Para HAZA DÍAZ, P., "la Ley vigente, recogiendo lo dispuesto en la Directiva 90/314/CEE, simplifica y reduce la clasificación de las empresas turísticas (...) a organizador y detallista, lo que significa, haciendo la comparación entre las distintas actividades de una y otra regulación -la administrativa y la civil- que ha desaparecido de ésta, como sujeto de la relación contractual de viaje combinado, lógicamente, la agencia mayorista, pues ésta puede tener relevancia en una norma administrativa que regula las posibles actividades de las agencias de viajes, pero es completamente indiferente para la regulación de un contrato que ha de vincular necesariamente a la empresa con el consumidor (...)"en El contrato de viaje combinado, La responsabilidad de las agencias de viajes, Marcial Pons, Madrid, 1997., pp. 59-70.

${ }^{74}$ La LT Cataluña, tras enumerar en el apartado $1^{\circ}$ del art. 54 las actividades de las agencias de viajes establece, en el apartado $2^{\circ}$ que "el ejercicio de las actividades a que se refiere el apartado 1 está reservado en exclusiva a las agencias de viajes (...)". En el mismo sentido se expresa el art. 59 LT Galicia.

75 Art. 29,1 LT Castilla y León; art. 17,a) LT Castilla-La Mancha; art. 32 LT Comunidad de Madrid; art. 36,1 LT Región de Murcia y art. 29,1 LT País Vasco. La LT País Vasco refuerza la reserva efectuada regulando el intrusismo profesional en su art. 33: "la realización o publicidad por cualquier medio de difusión de las actividades mercantiles propias de las agencias de viajes sin estar en posesión del correspondiente título se considera intrusismo profesional y sancionada administrativamente como falta grave". Por su parte, la LT Castilla-La Mancha incluye en el segundo grupo de empresas de mediación a "aquellas que tengan por objeto la comercialización, intermediación, organización y prestación de cualesquiera servicios turísticos cuando éstos no constituyan el objeto propio de la actividad de agencia de viajes y reglamentariamente se clasifiquen como turísticas" (Art. 17,b). 
Rioja añade a las anteriores, la comercialización ${ }^{76}$; y, finalmente la LT Canarias realiza la reserva más indefinida al establecer que (Art. 48,2): "La intermediación turística, en cuanto afecte a cualquier tipo de desplazamientos, sólo podrá realizarse por las agencias de viaje debidamente clasificadas e identificadas conforme reglamentariamente determine el Gobierno de Canarias". Las Leyes de Turismo del Principado de Asturias y Aragón, en cambio, reducen el ámbito reservado a las agencias de viajes, al establecido con carácter general por la Ley de Viajes Combinados, según hemos visto supra ${ }^{77}$.

En otros casos, consideramos que la reserva de exclusividad se regula de forma imprecisa. Así ocurre, por ejemplo, en la Ley de Turismo de la Comunidad de Valencia, que, sin especificar cuáles puedan ser las actividades propias de las agencias de viajes, se refiere a ellas para regular el intrusismo profesional: "El ejercicio de las actividades propias de las agencias de viajes sin estar en posesión del correspondiente título-licencia será considerado intrusismo profesional y sancionado conforme a lo dispuesto en esta Ley". (Art. 12). Postura similar adopta la Ley Foral de Turismo en Navarra, al referirse al intrusismo profesional en los siguientes términos: "La oferta al público de viajes, así como la realización o publicidad de las actividades mercantiles propias de las agencias de viajes, sin estar en posesión del correspondiente título-licencia, será considerada intrusismo profesional, salvo que se trate de las restantes empresas a las que se refiere este capítulo" (Art. 26,5). Esta determinación se completa con la reducción del campo de actuación que queda disponible para las denominadas «otras empresas de mediación»: "Las restantes empresas de mediación tendrán como única finalidad la comercialización común de ofertas de empresas turísticas limitando su actividad a la acogida o recepción de los usuarios turísticos en la Comunidad Foral de Navarra y a la prestación de servicios turísticos en este territorio" (Art. 27).

Sin embargo, aún contamos con un grupo de Leyes de Turismo (las correspondientes a las Comunidades Autónomas de Andalucía, Cantabria, Extremadura e Islas Baleares), que ni de una forma ni de otra contemplan en su

\footnotetext{
${ }^{76}$ Art. 18,1. La reserva a favor de las agencias de viajes que realiza la LT La Rioja se intensifica con las limitaciones que impone a las centrales de reserva que "no tendrán la capacidad para organizar viajes combinados, ni excursiones de un día y, en ningún caso, podrán percibir de los usuarios turísticos contraprestación económica por su intermediación" (Art. 18,2).

${ }^{77} \mathrm{El}$ art. 51,1 LT Principado de Asturias establece que "Se consideran agencias de viaje las empresas que, en posesión del título- licencia correspondiente, se dedican a la intermediación en la prestación de servicios turísticos, teniendo reservadas en exclusiva la organización y contratación de viajes combinados de conformidad con la legislación vigente". En el mismo sentido, art. 46,1 LT Aragón.
} 
articulado la reserva de actividades a las agencias de viajes. Por tanto, habremos de considerar que en estos supuestos, sólo quedan reservadas por Ley las actividades relacionadas con la organización, venta y realización de viajes combinados contemplada con carácter general, como se ha indicado, en la Ley de Viajes Combinados para todas las agencias de viajes. No parece apropiado, por tanto, en estos casos, reservar otras actividades a las agencias de viajes a través de normas reglamentarias, ante la ausencia de una clara disposición de remisión en la respectiva Ley autonómica.

El desarrollo reglamentario de las previsiones legales en el ámbito de la intermediación turística, en cambio, ofrece uniformidad en cuanto a la previsión y regulación de la reserva de exclusividad en beneficio de las agencias de viajes, ya se trate de reglamentos anteriores o posteriores a las respectivas Leyes de Turismo, incluso en aquellas Comunidades Autónomas cuyas Leyes no habían efectuado reserva alguna en dicho sentido. Esta reserva suele aparecer inicialmente, en la propia definición de agencia de viajes, como expresa, a modo de ejemplo, el art. 1,1 del reglamento de agencias de viajes de Castilla y León: "Son agencias de viajes las empresas que, en posesión del título-licencia correspondiente, se dedican profesional y comercialmente en exclusividad al ejercicio de actividades de mediación y/u organización de servicios turísticos, pudiendo utilizar medios propios en la presentación de los mismos". Adicionalmente, estas disposiciones incluyen una relación de las «actividades propias» de las agencias de viajes, sobre las que poseen el beneficio de exclusividad, así como, de las «actividades complementarias», que pueden realizar también otras empresas. Así, el art. 2,1 del Reglamento de Agencias de Viajes de Islas Baleares determina que son objeto o fines propios de estas empresas "a) La mediación en la venta de billetes o la reserva de plazas en toda clase de medios de transporte, así como en la contratación o reserva de habitaciones y servicios en las empresas turísticas y, particularmente, en los establecimientos de alojamiento turístico en todas sus modalidades, sin perjuicio de la facultad conferida por la legislación vigente a transportistas, hoteleros y otras empresas turísticas para contratar directamente con los clientes la prestación de sus propios servicios. La mediación y comercialización directa, mencionadas en el párrafo anterior, podrán ser realizadas a través de recursos informáticos y/o telemáticos de otras empresas o entidades, aunque no sean agencias de viajes, siempre que los mismos sean gratuitos para el consumidor; b) La organización, oferta y venta de los viajes combinados a los que se refiere la Ley 21/1995, de 6 de julio, reguladora de los Viajes Combinados; c) La organización y venta de las llamadas excursiones de un día ofertadas por las agencias de viajes o proyectadas a solicitud del cliente, a un precio global establecido y que no incluyan todos los elementos propios del viaje combinado; d) La ac- 
tuación como representante de otras agencias de viajes para la prestación en su nombre y a la clientela de éstas, de cualquiera de los servicios enumerados en el presente artículo; e) La prestación de otros servicios que se reconozcan como propios de su actividad de acuerdo con la legislación vigente". La exclusividad, como aclara esta disposición, no afecta a la contratación directa que puedan llevar a cabo las empresas de transporte de viajeros, los establecimientos hoteleros y demás empresas de alojamiento turístico para efectuar la contratación de sus servicios de forma directa con los clientes, salvo en cuanto se refiera a la venta de viajes combinados, que estas empresas no pueden comercializar de forma directa ${ }^{78}$.

También se refuerza la cláusula de exclusividad mediante la regulación y sanción del intrusismo profesional, entendiendo por tal la realización o publicidad por cualquier medio de difusión de actividades propias y exclusivas de las agencias de viajes, sin disponer del correspondiente título-licencia. En este sentido, todas las Leyes de Turismo han incorporado a su relación de infracciones administrativas en materia de turismo el ejercicio de actividades empresariales clandestina, es decir, sin el título o autorización que se precisa para su legal ejercicio ${ }^{79}$

Se determina como regla general que las personas físicas o jurídicas, instituciones, organismos y entidades, sean públicas o privadas que deseen promover la organización de viajes, han de encargar su organización técnica, la formalización de reservas y su ejecución a una agencia de viajes legalmente constituida, constando dicha circunstancia en la publicidad que se efectúe, indicándose el nombre, código de identificación y dirección de la agencia de viajes organizadora. Ésta asume, de esta forma, la responsabilidad en el cumplimiento de las condiciones en que se haya anunciado el viaje. No obstante, las disposiciones reglamentarias de algunas Comunidades Autónomas permiten excepcionar esta regla general, facilitando que entidades, asociaciones, instituciones y organismos puedan llevar a cabo la organización de viajes,

\footnotetext{
${ }^{78}$ El Reglamento de Agencias de Viajes de Cataluña introduce, además, la facultad que se concede a "las oficinas de turismo creadas y regidas por una Administración pública para efectuar reservas en alojamientos turísticos de su comarca, exclusivamente, para la primera noche de estancia, a petición de los turistas que se personen en la sede de la oficina" (Art. $2,2)$.
}

${ }^{79}$ Esta infracción es tipificada en algunas Leyes como grave y, en otras, como muy grave. 
siempre que cumplan las siguientes condiciones ${ }^{80}:$ a) Que la organización de los viajes se efectúe sin ánimo de lucro. b) Que se dirijan única y exclusivamente a sus miembros y no al público en general. c) Que no utilicen medios publicitarios para su promoción, ni sean de general conocimiento. d) Que se realicen de forma ocasional y esporádica. e) Que se organicen sin la apoyatura administrativa o de personal específica para la organización de tales viajes. Excepcionalmente el órgano competente de la Comunidad Autónoma podrá autorizar a determinados organismos públicos la organización y promoción de viajes, sin ánimo de lucro, en función de acuerdos o de su participación en organismos internacionales que exijan esta condición ${ }^{81}$.

Debemos, finalmente, hacer referencia a la exclusividad respecto a las centrales de reservas. Como se ha indicado anteriormente sólo algunas Leyes de Turismo mencionan en su articulado estas empresas ${ }^{82}$, limitándose, bien a incluir las centrales de reservas entre las empresas de intermediación turística ${ }^{83}$, bien a especificar sus funciones, especialmente diferenciándolas de las que corresponden a las agencias de viajes. En algunos casos las centrales de reserva sólo aparecen mencionadas, como una opción más entre las empresas de intermediación, como ocurre en las Leyes de Turismo de Cantabria, Castilla-La Mancha y Navarra ${ }^{84}$. Las notas que diferencian fundamentalmente los dos tipos de empresas radica en la actividad a la que se dedican, que en las centrales de reservas se reduce a la reserva de servicios turísticos, tal y como deter-

${ }^{80}$ Esta excepción no aparece en los Reglamentos de Agencias de Viajes de Canarias, Cantabria, Cataluña y Comunidad Valenciana. El RAV Andalucía exige, además, que se trate de entidades públicas o asociaciones privadas regidas por la Ley Orgánica Reguladora del Derecho de Asociación o clubes deportivos y que los viajes tengan relación directa con los fines de dicha asociación, entidad o club (Art. 27,4). El RAV Castilla y León exige que no se realicen bajo la modalidad de viajes combinados (Art. 3,2), aunque este requisito debemos extenderlo a todas las Comunidades Autónomas por imposición directa de la Ley de Viajes Combinados.

${ }^{81}$ El RAV Baleares incluye en esta excepción a otras entidades, asociaciones, etc., que organicen y promocionen viajes sin ánimo de lucro y les exige cumplir las condiciones indicadas en el apartado anterior. Vid. art. 18,4.

82 Concretamente las Leyes de Turismo de Andalucía, Aragón, Cantabria, Castilla-La Mancha, Navarra, Principado de Asturias y La Rioja.

${ }^{83}$ Esta postura es adoptada por las Leyes de Turismo de Cantabria, Castilla-La Mancha y Navarra.

${ }^{84}$ Art. 15,3 LT Cantabria; art. 17,c) LT Castilla-La Mancha y art. 25,2,c) LT Navarra. 
minan las Leyes de Turismo de Andalucía (Art. 47,4) ${ }^{85}$, Aragón (Art. 47), Principado de Asturias (Art. 52) y La Rioja (Art. 18,2), destacando como característica adicional, conforme establecen las Leyes de Andalucía y La Rioja, la prohibición de que perciban contraprestación económica alguna de los usuarios turísticos, por lo que habrán de recibir la misma de la empresa para la que efectúen la correspondiente reserva. Por tanto, hasta la fecha, las Leyes de Turismo no han establecido ninguna reserva material en exclusividad a favor de las centrales de reserva.

En cuanto a las disposiciones reglamentarias se refiere, hemos de partir de la limitación que impone el actual desarrollo reglamentario de las Leyes de Turismo, puesto que de las siete Leyes de Turismo que contemplan la existencia de centrales de reserva, sólo las correspondientes a Andalucía y La Rioja han tenido el adecuado desarrollo reglamentario posterior, la primera a través de un Reglamento de Agencias de Viajes y Centrales de Reserva ${ }^{86}$ y la segunda por medio de un Reglamento general de desarrollo ${ }^{87}$. Las restantes disposiciones reglamentarias, anteriores a las respectivas Leyes de Turismo, no efectúan mención alguna sobre estas empresas.

El Reglamento andaluz establece una reserva de exclusividad a favor de las centrales de reserva compartida con las agencias de viajes. Por una parte en su art. 3,a) reconoce el derecho de las empresas de mediación turísticas inscritas en el Registro a "desarrollar en exclusividad la actividad de mediación turística en las condiciones establecidas por el presente Decreto y demás disposiciones aplicables", reconociendo en su art. 8,1 el objeto propio ejercido por las agencias de viajes en régimen de exclusividad "con las excepciones previstas en este Decreto para las centrales de reservas". Finalmente, en el art. 29,1 determina que "son actividades de las centrales de reservas, compartidas con las agencias de viajes, las previstas en las letras b) y c) del artículo 8, apartado 1 . Por tanto, corresponden en exclusividad (junto a las agencias de viajes) a las centrales de

${ }^{85}$ Pertenecen al grupo de centrales de reserva quienes se dedican a la intermediación en la prestación de cualesquier servicios turísticos, sin que, en ningún caso, puedan percibir de los usuarios turísticos contraprestación económica por su intermediación.

${ }^{86}$ Aprobado por Decreto 301/2002, de 17 de diciembre, de agencias de viajes y centrales de reservas.

${ }^{87}$ Decreto $111 / 2003$, de 10 de octubre, que aprueba el Reglamento de desarrollo de la Ley 2/2001, de 31 de mayo, de Turismo de La Rioja. 
reserva ${ }^{88}$ : "La mediación en la reserva de plazas en cualquier alojamiento turístico" y "La mediación en la contratación de cualesquiera otros servicios turísticos prestados por las empresas turísticas reconocidas como tales por la Ley 12/1999, de 15 de diciembre, del Turismo, y demás normativa dictada en desarrollo de la misma".

Por su parte, el Reglamento General de la Ley de Turismo de La Rioja no efectúa ninguna reserva expresa y directa de funciones en beneficio de las centrales de reserva, dedicándose principalmente a diferenciar sus funciones respecto a las agencias de viajes para proteger la exclusividad de la que sí gozan éstas. Así, en primer lugar, en el art. 154 tras definir a las agencias de viajes y proclamar la exclusividad de sus funciones propias, establece que las centrales de reserva "Son las empresas y entidades que se dedican principalmente a reservar servicios turísticos de forma individualizada. Las centrales de reserva no tendrán la capacidad para organizar viajes combinados y, en ningún caso, podrán percibir de los usuarios turísticos contraprestación económica por su intermediación" y, finalmente, en su art. 180 determina las actividades de las centrales de reserva, sin imponer su exclusividad, y reiterando en su apartado $2^{\circ}$ la reserva a favor de las agencias de viajes: "1. Las centrales de reserva pueden desarrollar las siguientes funciones: a) Facilitar al consumidor o a las agencias de viajes información sobre proveedores de servicios turísticos que tengan en sus bases de datos. b) Poner en contacto a los consumidores y agentes de viajes con los prestadores de servicios turísticos. c) Formalizar las reservas entre los demandantes y los prestadores de servicios turísticos. d) Facilitar información sobre los recursos turísticos de la Comunidad Autónoma de La Rioja. 2. Las centrales de reserva no podrán realizar ninguna actividad propia o exclusiva de las agencias de viaje, salvo la organización de excursiones de un dia".

Aunque tratado de una forma residual, si el apartado $2^{\circ}$ del art. 180 trascrito permite que la central de reserva comparta una actividad exclusiva de las agencias de viajes "la organización de excursiones de un día", debemos inter-

\footnotetext{
${ }^{88}$ Según determina, por tanto, el Decreto 301/2002, las centrales de reserva no pueden realizar las siguientes funciones exclusivas de las agencias de viajes: La mediación en la venta de billetes y reserva de plazas en toda clase de medios de transporte; la organización o comercialización de viajes combinados, de acuerdo con la Ley 21/1995, de 6 de julio, Reguladora de los Viajes Combinados; la organización o comercialización de excursiones de duración no superior a veinticuatro horas o que no incluyan una noche de estancia, ofrecidas por la agencia o proyectadas a solicitud del usuario, por un precio global y la representación de otras agencias de viajes con la finalidad de prestar a su clientela, por cuenta y en nombre de aquéllas, cualesquiera de los servicios turísticos enumerados en este artículo.
} 
pretar que esta actividad se convierte así en exclusiva para ambos tipos de empresas de intermediación. Por último, debemos incluir en dicha reserva compartida la incluida en el art. 180,1,c) de "formalizar las reservas entre los demandantes y los prestadores de servicios turísticos", puesto que se trata de una actividad reservada también a las agencias de viajes, con la salvedad de que las centrales de reserva no pueden percibir retribución directa del usuario turístico y la agencia de viajes sí. Por tanto, aunque de forma indirecta, los artículos mencionados sí fijan un ámbito exclusivo en la actividad de las centrales de reservas, aunque sea compartido con las agencias de viajes.

\section{LA TÉCNICA DE LA RESERVA EN EL USO DE TÉRMINOS Y DE- NOMINACIONES LEGALES RELACIONADAS CON LA INTER- MEDIACIÓN TURÍSTICA}

Con frecuencia el ordenamiento ha impuesto restricciones en el uso de determinadas palabras o vocablos relacionados con la actividad turística, al objeto de amparar fines diversos. Entre ellos, destaca la protección del usuario turístico frente a actuaciones que pudieran ocasionarle algún tipo de error o confusión en la adopción de decisiones respecto a la contratación o utilización de servicios turísticos. En otros casos la restricción se dirige a preservar determinados términos para su uso exclusivo o limitado por la propia Administración, evitando, además, la confusión entre entidades o servicios públicos y los servicios ofertados por entidades privadas. Finalmente, también se hace uso de esta técnica con objeto de facilitar una mayor protección a las empresas y establecimientos autorizados frente a actuaciones abusivas, ilícitas e incluso clandestinas de entidades que carecen del título o autorización administrativa correspondiente y que, por tanto, incumplen los requisitos formales y materiales impuestos por el ordenamiento jurídico para la prestación de servicios turísticos con fines empresariales. Podemos citar, a modo de ejemplo, las limitaciones impuestas para el uso de las palabras «Parador de turismo», «Albergue de turismo», «Hostería de turismo» 0 «Refugio de turismo» ${ }^{89}$, o del término «turismo» o «turístico», que se reserva la Administración, o, finalmente, de las denominaciones legales que corresponden a las empresas turísticas y a sus respectivas categorías, tales como, hotel, pensión, hostal, apartamento turístico, campamento de turismo o camping, etc., cuyo uso queda reservado de forma exclusiva a los establecimientos y empresas que obtienen de

${ }^{89}$ Sobre estas limitaciones, véase, sucesivamente, la Orden de 5 de noviembre de 1940; Decreto de 4 de abril de 1952; Orden de 30 de septiembre de 1952 y Orden de 10 de enero de 1955. 
la Administración la correspondiente autorización, clasificación, especialización, modalidad, etc., que queda reflejada en el uso de los mencionados términos.

Las disposiciones que regulan la intermediación turística, a la vez que imponen requisitos, prohibiciones, y limitaciones, otorgan un determinado nivel de protección, especialmente frente a las entidades que no cumplen las mencionadas limitaciones. Así ocurre con las actividades de intermediación turística desde la primera reglamentación de 1942 en la que ya se determina que: "Nadie podrá usar el título de «agencia de viajes» sino en la forma y con los requisitos que el Decreto establece". En la siguiente reglamentación (1962) la protección respecto a la denominación se amplía, abarcando la exclusividad para denominarse agencia de viajes y para utilizar el término «viajes $»^{90}$. De forma similar se mantiene en la normativa de $1973-1974^{91}$ y en la ulterior de 1988, según el cual, "la condición legal y la denominación de agencias de viajes quedan reservadas exclusivamente a las empresas a que se refiere el apartado anterior. Los términos «viaje» o «viajes» sólo podrán utilizarse como todo o parte del título o subtítulo que rotule sus actividades, por quienes tengan la condición legal de Agencias de Viajes" ${ }^{92}$. Estas limitaciones de uso que implican reservas en beneficio de las empresas legalmente constituidas se han incorporado posteriormente tanto a las Leyes de Turismo ${ }^{93}$, como a los reglamentos de agencias de viajes aprobados por las Comunidades Autónomas.

Así pues, el grado de protección que el ordenamiento otorga a las empresas de intermediación en el ámbito de las denominaciones, puede concretarse en tres niveles. En primer lugar, mediante el otorgamiento en exclusiva de la condición legal de agencia de viajes, pues únicamente las entidades que cumplan los requisitos legalmente establecidos y hayan obtenido el correspondiente título-licencia habrán de ser consideradas legalmente como agencias de viajes. Esto implica que serán las únicas empresas que podrán llevar a cabo las actividades mercantiles reservadas de forma expresa por el ordena-

${ }^{90}$ Arts. 2 in fine y 3 del Decreto 735/1962, de 29 de marzo, que aprueba las normas reguladoras de las agencias de viajes.

${ }^{91}$ Art. 2 del Decreto 1524/1973, de 7 de junio.

${ }^{92}$ Art. 1,2 del Real Decreto 271/1988, de 25 de marzo.

${ }^{93}$ Se incluyen en las Leyes de Turismo de Andalucía, Castilla y León, Cataluña, Galicia, Navarra, Región de Murcia y Comunidad de Valencia. 
miento jurídico en exclusividad a las agencias de viajes, según hemos tratado anteriormente, además de beneficiarse de las medidas administrativas, especialmente de fomento y promoción dirigidas específicamente a ellas: inclusión en las guías oficiales, participación en campañas y actos promocionales de la Administración, ser beneficiarias de las medidas de fomento económico (ayudas, subvenciones, créditos oficiales), etc.; Un segundo nivel, consecuencia del anterior, implica la exclusividad en el uso de la denominación de «agencia de viajes», puesto que, su uso sin estar en posesión del correspondiente título-licencia es considerado por las Leyes de Turismo como infracción grave, por intrusismo profesional y clandestinidad y, por tanto, objeto del correspondiente procedimiento sancionador. Finalmente, la protección abarca la utilización, también de forma exclusiva, del término «viaje» 0 «viajes» en la denominación de la empresa, como parte de su título o subtítulo, impidiendo su utilización a las restantes empresas que no ostenten la condición legal de agencia de viajes. Esto permite singularizar la actividad de la empresa, utilizar dichas expresiones con carácter comercial y, al impedir su uso por empresas no legalizadas como agencias de viajes, evitan la confusión en los usuarios turísticos y el uso fraudulento de dichas denominaciones o términos protegidos.

Consideraciones similares a las efectuadas con las agencias de viajes podemos realizar en relación con las centrales de reservas, si bien en este caso nos encontramos ante una situación prácticamente generalizada de vacío normativo. En efecto, ninguna de las Leyes autonómicas de Turismo que se refieren a este tipo de empresa trata la protección de su denominación legal. Por su parte, de los únicos reglamentos que han regulado la constitución y funcionamiento de las centrales de reservas, correspondientes a las Comunidades Autónomas de La Rioja y Andalucía, sólo este último se refiere a la cuestión que tratamos, en su art. 3,b) al contemplar entre los derechos de las empresas de intermediación turística el de "utilizar en exclusiva las locuciones «agencia de viajes» $y$ «central de reservas», según proceda, con fines publicitarios, distintivos o identificativos de la empresa. Sin duda, la futura regulación de las actividades propias de las centrales de reserva al nivel en que en la actualidad se encuentran las restantes empresas turísticas, provocará un ámbito de protección hacia su denominación legal similar a la analizada en las agencias de viajes. 